\title{
Unwanted Accelerated Burning After Suppressant Delivery
}

Anthony Hamins

Kevin McGrattan

Glenn Forney

Sponsored by:

The Department of Defense Strategic Environmental Research and Development Program

The views and conclusions contained in this document are those of the authors and should not be interpreted as representing the official policies, either expressed or implied, of the Strategic Environmental Research and Development Program, NIST, or any other part of the U.S. Government. 
NIST Special Publication 1004

\section{Unwanted Accelerated Burning After Suppressant Delivery}

Anthony Hamins

Kevin McGrattan

Glenn Forney 


\title{
NIST Special Publication 1004
}

\section{Unwanted Accelerated Burning After Suppressant Delivery}

\author{
Anthony Hamins \\ Kevin McGrattan \\ Glenn Forney \\ Building and Fire Research Laboratory
}

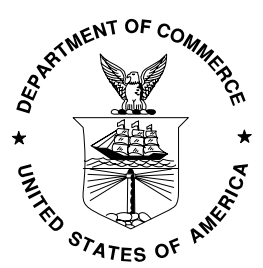

$\frac{\text { U.S. Department of Commerce }}{\text { Donald L. Evans, Secretary }}$

Technology Administration Phillip J. Bond, Under Secretary for Technology

National Institute of Standards and Technology Arden L. Bement, Jr., Director 
Certain commercial entities, equipment, or materials may be identified in this document in order to describe an experimental procedure or concept adequately. Such identification is not intended to imply recommendation or endorsement by the National Institute of Standards and Technology, nor is it intended to imply that the entities, materials, or equipment are necessarily the best available for the purpose.

National Institute of Standards and Technology Special Publication 1004 Natl. Inst. Stand. Technol. Spec. Publ. 1004, 48 pages (September 2003) CODEN: NSPUE2

For sale by the Superintendent of Documents, U.S. Government Printing Office Internet: bookstore.gpo.gov — Phone: (202) 512-1800 — Fax: (202) 512-2250 Mail: Stop SSOP, Washington, DC 20402-0001 


\section{Executive Summary}

In a number of real-scale fire tests, accelerated or enhanced unwanted burning has been observed immediately following the delivery of a fire suppressant. The conditions under which this phenomena occurs, its potential for harm, and its effect on the ability of an agent to extinguish a fire have not been comprehensively documented. The objective of this work is to identify the causes of enhanced burning with an emphasis on aircraft dry bay and engine nacelle applications and to provide recommendations on how it can be avoided when it may become a significant safety risk.

A survey of the fire and combustion literature was undertaken to document cases of enhanced burning after suppressant delivery. Informal interviews were conducted with a sample of scientists and engineers involved with full and reduced-scale fire suppression experiments. Analysis of the information suggests that there is no common terminology or unique definition used to describe unwanted enhanced burning. Several instances of enhanced burning have been documented and it is apparent that unwanted enhanced burning is not uncommon. Manifestation of the phenomena has been documented through measurements of increased pressure, temperature, and heat release rate, as well as changes in the appearance (intensity, color, volume) of a fire for a number of experimental configurations. Although many events could be described as enhanced unwanted burning after suppressant delivery, the main hazard associated with this phenomena appears to be system over-pressurization due to enhanced combustion from a vaporizing liquid fuel that mixes with air after suppressant delivery. In many instances, the phenomena do not represent a significant safety risk.

To further understand the phenomena, three experiments in which system overpressurization was suspected were analyzed in some detail. The cases involved overpressurization of full-scale suppression experiments for an aircraft dry bay and two cases of over-pressurization of full-scale enclosure fire experiments. The three cases had many differences in terms of experimental conditions, time scales of the suppression events, and the geometric configuration of the experiments, yet in all three cases volatile liquid fuels were present. When wood, a solid-phase fuel, was substituted for liquid fuels in the suppression experiments in an enclosure (Case 2), large pressure fluctuations were not 
observed. The case studies were analyzed using differing approaches, depending on the details of the scenario.

The first case-study examined was that of enclosure fires conducted at the Naval Research Laboratory (NRL) in which it was documented that suppressant discharge can cause significant fire flare-up and pressure increases for unconfined volatile liquid fuels in the presence of a hot ignition source. Deflagration was observed for HFC agents, water mist, and hybrid agents involving HFC/powder mixtures. The results showed that suppressant delivery caused an intensification of the fire as defined by an increase in the flame volume, suggesting that (premixed) fuel-air mixtures can be created in a postsuppression environment under certain conditions. Interestingly, all deflagrations observed were in the presence of a hot ignition source (at $\approx 550$ oC). An analysis of the detailed experimental data provided by Sheinson and coworkers suggest that unwanted burning effects occurred when there was insufficient suppressant to assure suppression and prevention of re-ignition. In this sense, unwanted accelerated burning effects are already embedded in the design equations resulting from full-scale test results.

The second case-study involved the unanticipated catastrophic over-pressurization that destroyed a C-130 Wing Leading Edge Dry Bay Test Facility on August 28, 1998 during real-scale fire suppression testing. Six tests previous to the catastrophic event using $\mathrm{N}_{2}$-pressurized HFC-125 had led to routine suppression results. The seventh test was designed to test the impact of the $\mathrm{N}_{2}$ used for pressurization on the fire. An Air Force investigation of the event concluded that "increased level of fluid ignition (combustion)" was the source of over-pressure. Experimental peculiarities were noted including the use of a suppressant delivery line that was air-filled.

The fire scenario was extremely complex due to the presence of a ballistic round, accompanying shock waves, fuel splashing (two-phase flow), multiple ignition sources (hot shrapnel), and so on. It should be noted that according to measurements made during the experiment, failure of the C130 dry bay fixture occurred when the pressure inside of the apparatus reached $54 \mathrm{kPa}$ (7.8 psig). The apparatus had survived earlier experiments when the pressure reached $30 \mathrm{kPa}$ (4.3 psig). A plausible explanation for the overpressurization is that delivery of the agent in this case caused enhanced mixing of unburnt fuel and air. The experiment used an inert suppressant $\left(\mathrm{N}_{2}\right)$, but at a volume fraction that 
was $0.4 \%$ of the cup burner value, an amount that would have little impact on the stability of the fire and certainly would not extinguish the fire.

To better understand the conditions in the dry bay during fire suppression, an analytic approach was taken to simulate the pressure in the enclosure. The time associated with equilibration of a pressure wave within the dry bay was estimated to be less than $1 \mathrm{~ms}$, whereas the timeline associated with the spray fire was on the order of $\approx 100 \mathrm{~ms}$, which allowed application of the incompressible form of the conservation equations.

The third case-study examined pressure fluctuations observed by Kashiwagi et al. [2000] during suppression experiments on moderate-sized $(\approx 400 \mathrm{~kW})$ heptane pool-fires in an enclosure. The experiments were simulated using the NIST Fire Dynamics Simulator [McGrattan et al., 2000] with a one-step chemical reaction. Numerical prediction of the time dependent enclosure pressure and the amount of agent required to suppress the fire yielded predictions that were very sensitive to the Arrhenius rate parameters. Using Arrhenius rate parameters that correspond to measurements in smallscale suppression experiments failed to yield pressure fluctuations similar to those observed by Kashiwagi et al. [2000].

In summary, the main hazard associated with unwanted burning after suppressant delivery appears to be over-pressurization likely due to enhanced mixing of vapor with air. From the investigation of three key case studies, the most important overall finding is that suppressant delivery does not appear to pose undue safety risk unless insufficient amounts of suppressant are applied to a fire. It is concluded that these effects are already embedded in full-scale test results and associated design equations. This report concludes with a discussion of safety issues associated with unwanted enhanced burning after suppressant delivery. 


\section{Table of Contents}

Page

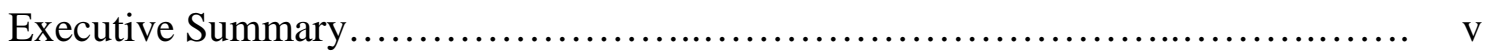

1. Technical Problem .......................................................... 1

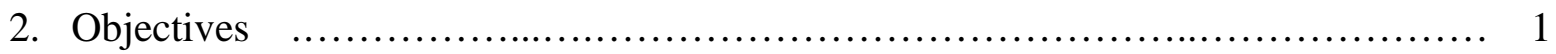

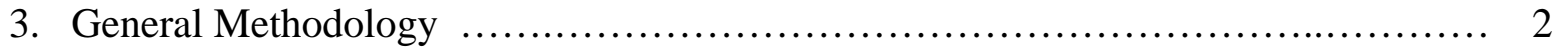

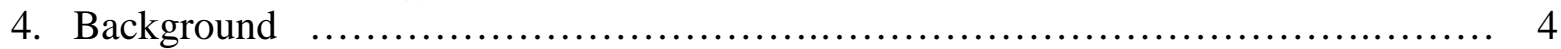

4.1 Interview Findings: Full-Scale Suppression Testing $\ldots \ldots \ldots \ldots \ldots \ldots \ldots \ldots \ldots \ldots . \ldots$

4.1.1 Large Pressure Fluctuations \& Over-Pressurization ................... 6

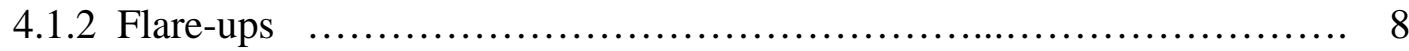

4.2 Literature Review \& Interview Findings: Bench-Top Experimentation ........ 11

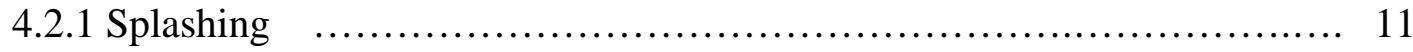

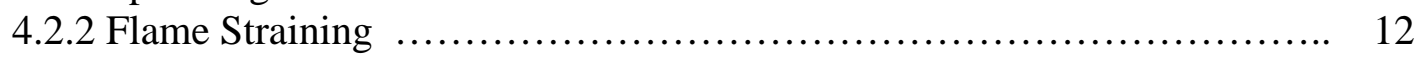

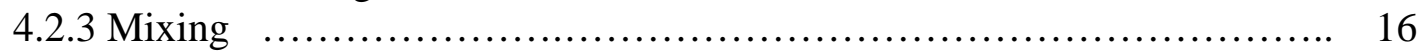

4.2.4 Heat Transfer and Chemistry-Related Effects $\quad \ldots \ldots \ldots \ldots \ldots \ldots \ldots \ldots \ldots . . \ldots \ldots$

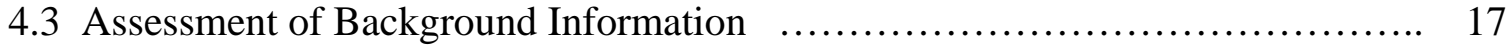

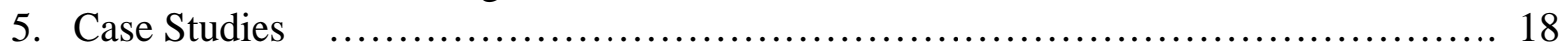

5.1 Case 1: Analysis of Over-Pressurization during Suppression in the

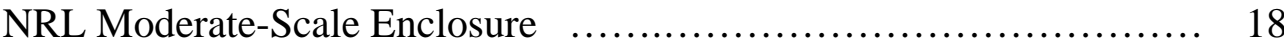

5.2 Case 2: Modeling of Global Properties during Fire Suppression in a Dry bay ... 24

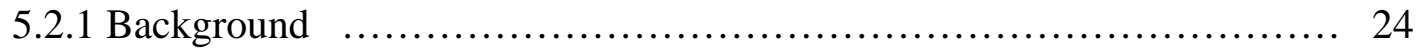

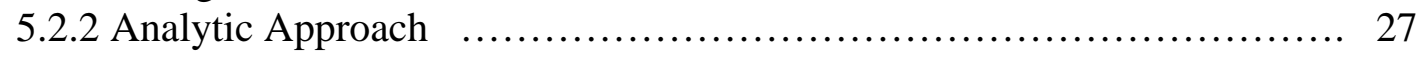

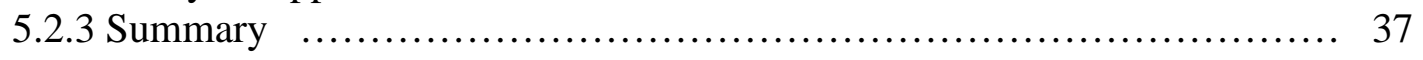

5.3 Case 3: Pressure Fluctuations During Suppression in an Enclosure ........... 38

5.4 Accelerated Burning in an Engine Nacelle ............................... 41

6. Summary, Conclusions, and Recommendations for Future Research .............. 42

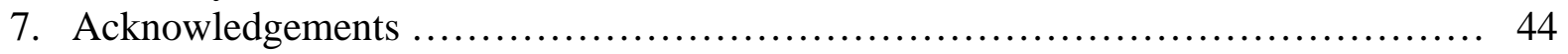

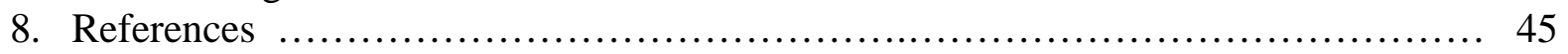




\section{Technical Problem}

Over the last decade, there has been a world-wide research effort to find long and short term alternatives to ozone depleting halon fire suppressants. This has led to testing of candidate agents in reduced and full-scale fire suppression testing. A key tenet of fullscale testing is to maximize fire suppression efficiency while minimizing the amount of stored agent necessary for complete suppression. This optimization demands a better understanding of the behavior of fires during the suppression process. One part of the suppression process that is not well understood is the "enhanced burning", which has been observed just after an extinguishing agent has been applied to a fire.

In a number of real-scale fire tests, accelerated or enhanced unwanted burning has been observed immediately following the delivery of a fire suppressant. The phenomena may manifest itself in a variety of forms including a fire flare-up or a sudden enclosure over-pressure. The phenomena is associated with the delivery of a suppressant and would not occur without a suppressant discharge.

A literature review reveals that there have been few published descriptions of enhanced burning during suppressant deployment. Reports of the phenomena have largely been anecdotal rather than scientifically rigorous. Little analysis has been conducted considering the implications of the observations.

The conditions under which accelerated burning occurs, its potential for harm, and its effect on the ability of an agent to extinguish a fire are currently unknown. While this behavior could pose a significant safety risk, there has been no systematic study investigating the conditions necessary for the existence of this phenomenon. Enhanced burning could potentially pose a safety risk if it causes structural damage, strengthens a fire enough such that it survives extinguishment, or increases the likelihood of unwanted re-ignition or fire spread.

\section{Objectives}

The objective of this work was to identify the causes of enhanced burning after extinguishing agents are applied to fires with an emphasis on aircraft dry bay and engine nacelle applications, and to provide recommendations on how enhanced burning can be avoided when it becomes a significant safety risk. 


\section{General Methodology}

The technical approach and methodology used in this research are shown schematically in Figure 1. The approach consisted of a literature review, an informal survey of fire suppression practitioners, and detailed analysis of the phenomena when it appeared to pose a significant safety risk. Because the number of documented cases where the phenomenon was identified or suspected was small, the study focused on an analysis and investigation of case studies identified by practitioners of fire suppression testing and research.

To further understand the phenomena, calculations were undertaken when appropriate. In one case, these focused on simple bracketing estimates of pressure increase in an enclosure due to suppressant release and enhanced combustion. A second case was suited for computational fluid dynamic (CFD) fire modeling. An attempt to do this was unsuccessful due to the complexity of the scenario and the current limitations of CFD fire models. This report concludes with a discussion of safety issues associated with unwanted enhanced burning after suppressant delivery.

The approach was developed based on the fact that little is known about the phenomena. The approach consciously does not consider characterization of the splashing of a fuel by a high momentum agent stream, which was the approach initially proposed as part of this project. This does not imply that splashing is not particularly dangerous. A splashing fuel spray can enlarge the surface area of a burning material, leading to a condition that is potentially difficult to extinguish. Subsequent analysis suggested that while a study of splashing may lead to interesting new information, such information would not aid in the analysis of unwanted accelerated burning. In addition, it is a given that splashing of a fuel pool will occur when impinged by a high momentum agent stream. It was decided that detailed investigation of the splashing phenomena would not lead to insight into how to prevent unwanted burning after suppressant delivery. The solution to the splashing problem is self-evident and involves directing the high momentum agent discharge away from possible fuel sources.

The effort discussed in this report instead focused on other issues associated with the unwanted accelerated burning phenomena, namely, over-pressurization of the 
enclosure by ignition of a combustible fuel vapor-air mixture. The worst case would be the case of a uniform stoichiometric mixture throughout the enclosure. Ignited at one end of the enclosure, it would propagate at its turbulent flame speed ( $O[10 \mathrm{~m} / \mathrm{s}])$, heating and expanding until it reached the other end of the nacelle.

The remainder of Section 1 of this report contains a description of the phenomena, a literature review, and the results of an informal survey of a number of scientists and engineers conducting full-scale fire suppression research and testing. Section 2 contains an analysis of three case studies including two enclosure fires and a fire in a dry bay. Section 3 contains summaries of the findings and makes conclusions regarding avoidance of enhanced burning after suppressant delivery.

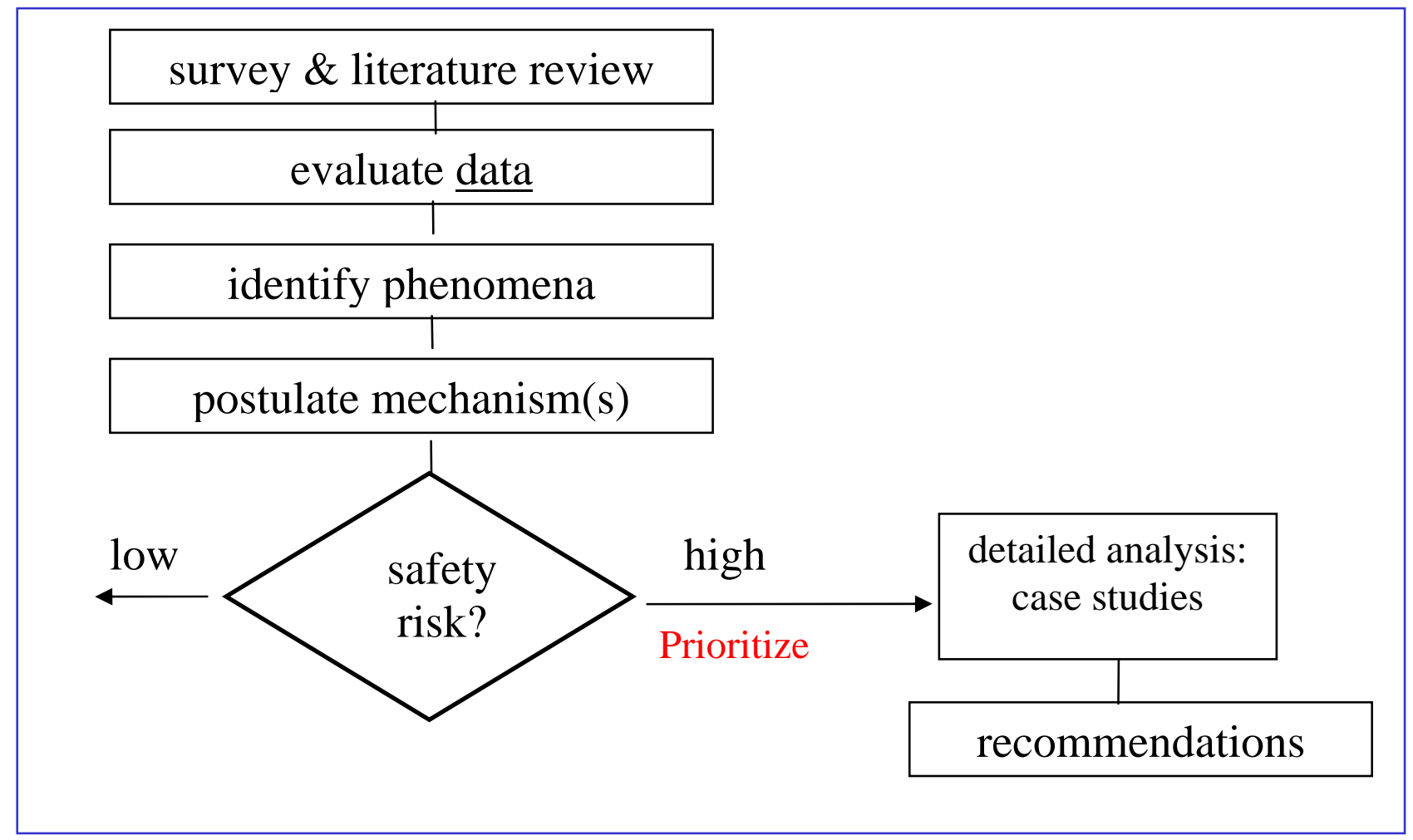

Figure 1. Flowchart outlining the research approach taken in this study. 


\section{Background}

Several instances of enhanced burning have been documented in the literature and it is apparent that unwanted enhanced burning after suppressant delivery is not uncommon. Yet, analysis of information available in the literature indicates that there is no unique definition to describe unwanted enhanced burning. In general, the phenomena are not well understood or recognized. Because of this situation, there is no common terminology to describe the phenomena, which hampers progress in this area.

A review of the literature and discussion with other researchers indicates that evidence of the phenomena of unwanted burning after suppressant delivery is typically anecdotal, rather than scientific in nature. Manifestation of the phenomena has been documented through measurements of increased pressure, temperature, or heat release rate after suppressant delivery, as well as observed changes in fire appearance (intensity, color, volume). The phenomena have not been limited to one particular suppressant type or configuration. Observations of the phenomena have been made in a number of very different configurations including full and reduced-scale experiments on aircraft dry bays and enclosure fires. To date, there has been no comprehensive study of this phenomenon or its possible ramifications in terms of fire suppression and life safety.

A survey of the fire and combustion literature was undertaken to document cases

of enhanced burning after suppressant delivery. In addition, a number of interviews were conducted with researchers involved in full and reduced-scale fire suppression experiments.

\subsection{Interview Findings: Full-Scale Suppression Testing}

Interviews were conducted with those directly involved with full-scale suppression testing on engine nacelle, dry bay aircraft fire safety, and vented and unventilated enclosure fires. Interviews were conducted during the years 2001 and 2002 with personnel performing experiments at Wright Patterson Air Force Base (WPAFB) [Bennett, 2002; Tucker, 2002; Cyphers, 2002], the Naval Research Laboratory (NRL) [Sheinson, 2002; Maringhides, 2002], NAVAIR at Lakehurst [Tedesci, 2002; Wolf, 2002], the Research Institute of Fire and Disaster of Japan (RIFD) [Saso, 2002], the Federal Aviation Administration (FAA) [Ingerson, 2002; Rhinehart, 2002], and the 
Aircraft Survivability Division, U.S. Navy Facility at China Lake, CA (China Lake) [Manchor, 2002] as listed in Table 1.

The interviews and literature search provided information on the multiplicity of scenarios, conditions, configurations, and suppressant types that are relevant to the discussion of unwanted burning. A number of observations are noted below that appear to be related to unwanted enhanced burning or combustion after suppressant delivery. Almost all investigators involved in full and reduced-scale suppression experiments have observed "flare-ups" of a fire after suppressant delivery. In a "flare-up", the luminosity and volume of the fire appear to rapidly increase immediately after suppressant deployment as additiont of the suppressant causes displacement of flames, fuel vapors or hot combustion products. Several investigators involved in full and reduced-scale suppression experiments observed over-pressurization of the test enclosure.

\begin{tabular}{|c|c|c|}
\hline \multicolumn{3}{|c|}{ Configuration } \\
\hline Nacelle & Dry Bay & Enclosure \\
\hline Bennett, Tucker (WPAFB) $^{1}$ & Cyphers (Skyward) ${ }^{2} \checkmark$ & $\begin{array}{l}\text { Sheinson, Maranghides } \\
\text { (NRL) })^{3}\end{array}$ \\
\hline Ingerson (FAA) $^{4}$ & Manchor (China Lake) $^{5}$ & Saso (RIFD) ${ }^{6} \checkmark$ \\
\hline $\begin{array}{c}\text { Tedeschi (NAVAIR }{ }^{7} \\
\text { Lakehurst) }\end{array}$ & Wolf (NAVAIR Lakehurst) $^{7}$ & Rhinehart (FAA) $^{4}$ \\
\hline \multicolumn{3}{|c|}{$\begin{array}{l}\text { Indicates that over-pressurization of enclosure after suppressant delivery observed. } \\
\text { 1. Wright Patterson Air Force Base, Dayton, Ohio. } \\
\text { 2. Skyward, Ltd., Dayton, Ohio. } \\
\text { 3. Naval Research Lab, Washington, D.C. } \\
\text { 4. Federal Aviation Administration, William J. Hughes Technical Center, Atlantic City, } \\
\text { New Jersey. } \\
\text { 5. Naval Ordnance Test Station, China Lake, California. } \\
\text { 6. Research Institute of Fire and Disaster, Mitaka, Japan. } \\
\text { 7. Naval Air Systems Command, Lakehurst, New Jersey. }\end{array}$} \\
\hline
\end{tabular}




\subsubsection{Observation of Large Pressure Fluctuations and Over-Pressurization}

Of the several observations detailed by those performing full-scale fire suppression testing, one particular type of event appeared to be particularly hazardous. Several investigators involved in full and reduced-scale suppression experiments observed over-pressurization of the test enclosure (see notes in Table 1). This situation was observed in unventilated and slowly ventilated enclosure fires, as well as a Dry bay Test Facility. The phenomena are described in more detail below. Whereas there were a number of commonalities between these three cases, there were many more differences, for example, in ventilation and clutter conditions, suppression timescales $(\Delta t)$, and configuration type, as seen in Table 2. The most hazardous pressure excursions occurred for the configurations with a re-ignition source present. The one commonality of note was that volatile liquid fuels were present in all cases. When wood replaced heptane in Configuration 3, pressure fluctuations were not observed.

\begin{tabular}{|c|c|c|c|c|c|}
\hline Configuration & $\begin{array}{c}\text { Re-ignition } \\
\text { Source }\end{array}$ & Ventilation & Clutter & $\begin{array}{c}\Delta \mathrm{t}(\mathrm{s}) \\
\text { suppression }\end{array}$ & Fuel \\
\hline $\begin{array}{l}\text { 1. Enclosure } \\
(\mathrm{NRL})\end{array}$ & Yes & None & High & $\approx 10$ & $\begin{array}{c}\text { Methanol- } \\
\text { Heptane }\end{array}$ \\
\hline $\begin{array}{l}\text { 2. Dry bay } \\
\text { (C130 WPAFB) }\end{array}$ & Yes & $\begin{array}{l}\text { Projectile } \\
\text { damage }\end{array}$ & Low & $\approx 0.1$ & JP8 \\
\hline $\begin{array}{l}\text { 3. Enclosure } \\
\text { (RIFD) }\end{array}$ & No & Mechanical & None & $\approx 10$ & Heptane* \\
\hline
\end{tabular}

Over-pressurization was observed and reported in the literature by experimentalists investigating fire suppression in ventilated and unventilated enclosure fires. To further understand the most hazardous phenomena, analyses were carried out on three experiments in which system over-pressurization was suspected. The cases 
involved over-pressurization of full-scale suppression experiments for an aircraft dry bay and two cases of over-pressurization of full-scale enclosure fire experiments. The three cases had many differences in terms of experimental conditions, time scales of the suppression events, and geometric configuration of the experiments, yet in all three cases volatile liquid fuels were present. When wood, a solid-phase fuel, was substituted for the liquid fuel in the suppression experiments in an enclosure (Case 3), the amplitude of the pressure fluctuations were reduced. The case studies were analyzed using approaches tailored to each incident, depending on the details of the scenario. A brief synopsis of the three cases follows with a more detailed analysis given below.

\section{Case 1: Analysis of Over-Pressurization during Suppression in the NRL Moderate-Scale} Enclosure

Sheinson and coworkers of NRL have shown that a suppressant discharge in a moderate-scale enclosure $\left(28 \mathrm{~m}^{3}\right)$ can cause significant fire flare-up and lead to rapid pressure increases for unconfined volatile liquid fuels in the presence of a hot ignition source [Maranghides and Sheinson, 2000]. Some aspects of the experiments are described in Table 2 (above). In their experiments, repeatable rapid over-pressurization was often observed after suppressant delivery, which was attributed to a combustion/deflagration wave. A variety of suppressant types were used including gaseous, compressed liquid, and hybrid suppressants composed of liquid-phase plus dry powder. Through the analysis of video records, the experiments documented that suppressant delivery could cause intensification of the fire and an increase in the burning area. Because an ignition source was present throughout the experiments, it was unclear whether the deflagration initiated due to a failure to fully suppress the initial fire or as a re-ignition after complete suppression.

\section{Case 2: Over-Pressurization during Fire Suppression Testing in the C130 Dry Bay} Facility at WPAFB

In a replica of a C130H WLE Dry bay test article, unanticipated catastrophic failure occurred after suppressant delivery failed to extinguish an experimental fire. An incident investigation suggested that the release of agent ( $\mathrm{N}_{2}$ in this case) may have acted 
to mechanically agitate the air, contributing to a more vigorous and rapid combustion event. In the post-suppression environment of an enclosure fire, deflagration and overpressurization was attributed to enhanced mixing of unburned vapor/air mixtures.

\section{Case 3: Total flooding suppression of a pool fire in an enclosure at RIFD, Japan}

A series of total flooding suppression experiments were performed using heptane pools fire in an enclosure at RIFD, Japan [Kashiwagi, 2001]. The suppressants tested included gaseous inert mixtures as well as compressed halogenated liquids. A door (closed before suppressant delivery) and a small vent near the ceiling provided ventilation. Pressure fluctuations were observed in the enclosure after suppressant delivery. No controlled ignition source was present in the enclosure, although the hot metal burner or fire-heated thermocouples could have acted as an ignition source. The reasons for the pressure fluctuations are not clear. It is possible, however, that the fluctuations were due to dynamics of the suppressant flow shielding air from fuel. Kashiwagi et al. [2001] highlight the importance of the pressure fluctuations, stating that, “agent discharge enhances flame intensity.... over-pressurization during suppression is caused not only by the agent discharge but also by the expansion of gases due to the combustion... application of the total-flooding systems to volatile liquid fuel fires has potential risk of compartment destruction due to the rapid mixing of unburned vapor with air.”

\subsubsection{Flare-ups}

While a high momentum suppressant discharge in an engine nacelle or dry bay may or may not extinguish a fire, the discharge can significantly alter the flowfield. In such a case, the suppressant flow may cause displacement of flames, fuel vapors or hot combustion products associated with the fire. This may include smoke, $\mathrm{CO}_{2}$, and water vapor. A dramatic example of such a situation is shown in Fig. 2, which illustrates a typical flare-up observed during full-scale V-22 fire suppression experiments at the China Lake test facility. Flare-ups were also been observed immediately after suppressant delivery in reduced-scale experiments such as a turbulent spray burner in a wind tunnel 
[Hamins et al., 1994] and the Wright Patterson Engine Nacelle Test Facility [Tucker, 2002].

In the China Lake experiments, a solid propellant gas generator was used to extinguish a fire in the wheel bay area, which is to the right in the images shown in Fig. 2. The images in Fig. 2 are taken approximately $0.4 \mathrm{~s}$ after generator deployment in the adjacent volume on the right. Flames appear to be pushed into adjacent volumes that are in communication (have an opening) with the primary protected volume. This is likely due to the rapid volume displacement caused by the effluent of the solid propellant gas generators that occurs within the protected volume, which tends to push the hot gases, fuel vapors, and flames through the opening into the adjacent volume [Manchor, 2002]. Similar observations were made in many other experimental facilities with other suppressant types. For example, in the case of the NIST turbulent jet spray burner, gaseous suppressant release caused sudden changes in the appearance of the fire [Hamins et al., 1996]. The danger posed by a flare-up relates to the possible ignition of a fuel puddle or leak that may be present in the vicinity of the flare-up. The duration of a flareup can be expected to be on the order of the duration of the suppressant release. The intensity of a flare-up is related to the relative location of the fire to the suppressant release and its momentum. If suppression occurs, then the extended flame which is downstream of the flame anchoring region can be expected to disappear only after flame extinguishment occurs near the flame anchoring position. If suppression does not occur then the flare-up will disappear and the flame will return to its previous appearance.

Heat transfer from a flare to a nearby object could lead to ignition depending on the critical ignition temperature and the duration of flame impingement. An increase in a material's temperature depends on the thermal inertia of the object, and the amount and duration of the heat flux. The duration of the heat flux due to flame impingement from a flare could be expected to be less than or equal to the time of the suppressant delivery that typically varies from $1 / 4 \mathrm{~s}$ from a gas generator to several seconds for a compressed liquid discharge. Direct flame impingement on a surface would cause ignition of many liquid fuels with flash points above ambient temperature. 

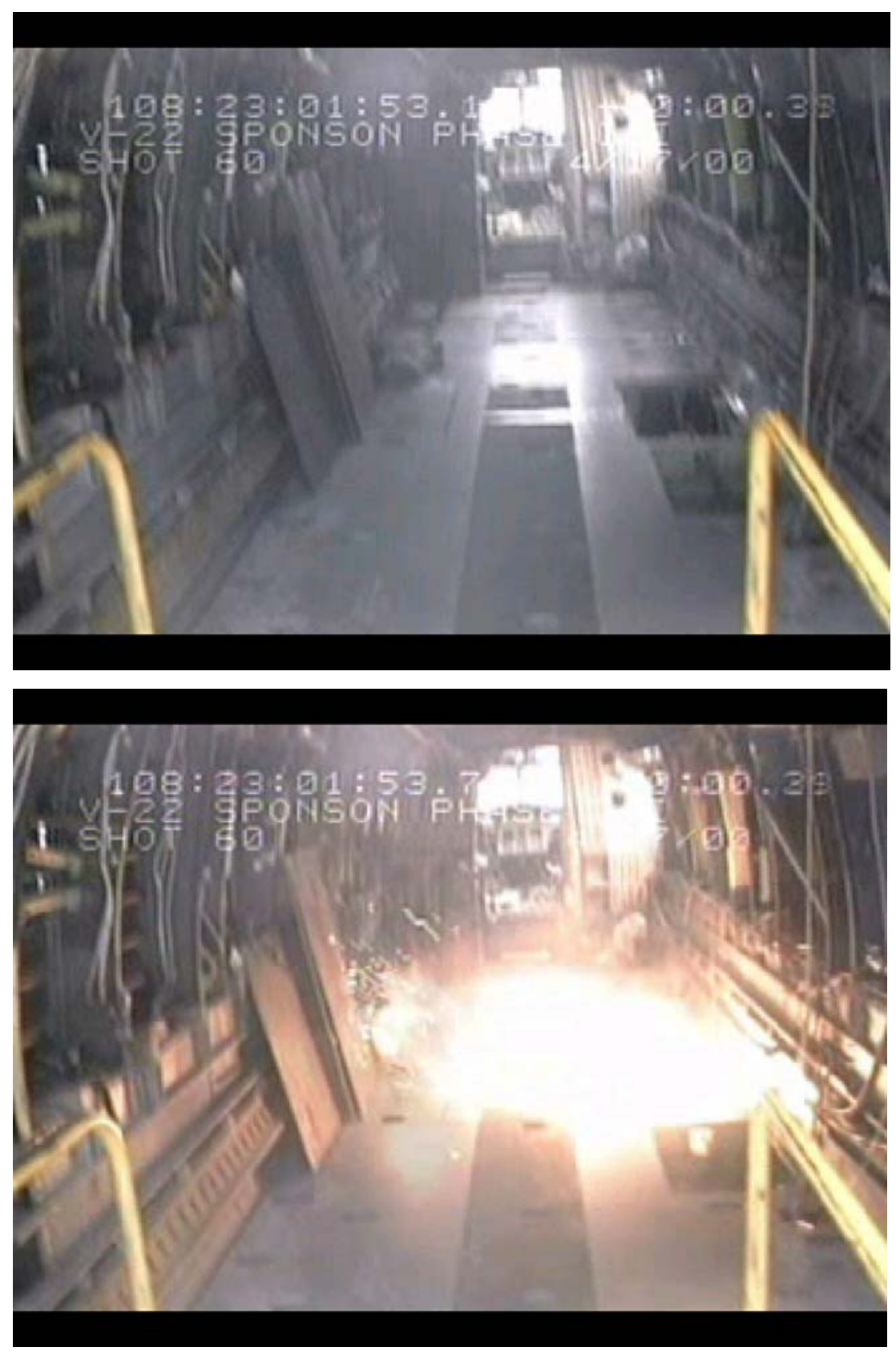

Figure 2. Flare-up observed during full-scale V-22 fire suppression experiments at the China Lake test facility when gas generators are used to extinguish fire in a dry bay area. Top and bottom images were taken approximately $0.6 \mathrm{~s}$ apart. The top image was taken just after release of a solid propellant gas generator in the wheel bay, which is a volume adjacent to the right of the images. 


\section{$\underline{4.2 \text { Literature Review and Interview Findings: Bench-Top Experimentation }}$}

Unwanted enhanced burning after suppressant delivery may occur through flowrelated effects that involve fuel splashing or flame straining. Although these effects are due to the consequences of the discharge of the suppressant, they are each distinct in their form. Other mechanisms may also contribute to accelerated burning. For example, it was shown that halogenated agents can enhance soot formation and heat release rate in benchscale flame experiments [Smyth and Everest, 1996; Homstedt et al., 1993].

\subsubsection{Splashing}

In engine nacelle and dry bay applications, suppressant delivery is typically a high momentum two-phase (liquid and gas) jet. Fast, high momentum suppressant application was shown to be advantageous in terms of suppressant mass requirements [Hamins et al., 1994]. In aircraft applications, agent is often delivered through a dispersing nozzle or simply through a hollow tube. The suppressant discharge may or may not be directed at the fuel source of the fire. If the suppressant is aimed directly at a liquid fuel source, the momentum associated with suppressant delivery can cause splashing of the liquid fuel, impacting the character of the burning fire. Given sufficient momentum, the suppressant discharge can cause the ejection of liquid droplets from the burning fuel surface.

Yang and coworkers demonstrated the impact of a high momentum jet on the burning of a liquid hydrocarbon diffusion flame [Yang, 2002; Pitts et al., 1994]. In their experiments performed at NIST, gaseous nitrogen or HCFC-22 was released from a pressurized cylinder (4.1 MPa or 600 psig), which was located $1.6 \mathrm{~m}$ directly above a $10 \mathrm{~cm}$ diameter liquid pool of burning heptane. A fast opening solenoid valve controlled the suppressant discharge. Figure 3 shows a series of frames from high speed filming (250 frames/s) of gaseous $\mathrm{N}_{2}$ delivery onto a burning heptane pool fire. The total time elapsed between frames 3(a) and 3(f) was approximately 0.5 s. Image analysis showed that the velocity of the $\mathrm{N}_{2}$ stream was approximately $90 \mathrm{~m} / \mathrm{s}$.

Figure 3a depicts the fire just before the $\mathrm{N}_{2}$ release. It is a typical pool fire with the flames forming a characteristic plume shape above the fuel surface. Figure 3b shows that within a few milliseconds after agent release, the gas-phase flame is disrupted and appears to be squashed or compressed. After $20 \mathrm{~ms}$, Figure 3c shows that the flame 
appears to be extinguished. Small pockets of flame appear to remain about the periphery of the burner. Figure $2 \mathrm{~d}$ shows the liquid fuel splashing about $80 \mathrm{~ms}$ after the release. A significant amount of fuel atomization was evident. The atomized fuel mixed with the surrounding air and burning of the fuel/air mixture occurred despite the presence of the agent. The occurrence of combustion in this scenario is governed by the mixing dynamics of the fuel, the air and the suppressant. Figures 3e and 3f, photographed about $300 \mathrm{~ms}$ and $500 \mathrm{~ms}$ after the release, respectively, show the formation of a large volume of flame. The visible flame area can be thought of as representative of the degree of fire enhancement. As the flame area increases, the fire heat release rate increases. In this manner, the images clearly demonstrate enhanced burning. Similar behavior was observed by Yang and Pitts [1994] during release of the compressed liquid $\mathrm{CHF}_{2} \mathrm{Cl}$ (HCFC-22) above the $10 \mathrm{~cm}$ heptane pool fire, despite the fact that HCFC-22 is almost a factor of three times more effective a suppressant than $\mathrm{N}_{2}$, on a volumetric basis [Hamins et al., 1994].

Yang and Pitts observed that the delivery of a high momentum jet enhances the burning rate of the pool fire as the liquid fuel is forced from the burner. As this happenned, the flame luminosity increased and the effective burning area appeared to increase. The fact that the jet was composed of a suppressant did not assure that burning was suppressed throughout the flowfield. Fire suppression was assured only at locations with sufficient suppressant volume fraction. Thus, the dynamics of the agent flow control combustion and suppression of the pool flame. While there may be many effective strategies for extinguishing a $10 \mathrm{~cm}$ pool fire using a gaseous agent, a high momentum agent jet is not effective, due to fuel splashing and non-uniform agent mixing.

Although the splashing phenomena were documented through the suppression experiments described above, there is little understanding of the splashing behavior of a liquid fuel puddle subjected to a high momentum fluid jet. Trabold and Obot [1997] investigated the onset of splashing from free liquid surfaces exposed to impinging gas jets. Predictive equations for the critical mean nozzle exit velocity at the onset of liquid splashing were developed in terms of the relevant flow, geometric, and physical parameters. At a critical jet momentum, splashing occurs whereby droplets are ejected from the liquid surface. Yet there is no known available data on the dynamic spatial 
distribution and momentum of a splashing liquid and its interaction with an impinging jet or spray.

The ejection of burning liquid fuel drops may subsequently be transported to a location where ignition of non-combusting fuel could occur. Such a scenario is possible if the suppressant is a high momentum gaseous jet, but it is also possible if the suppressant is a low momentum liquid spray, emanating, for example, from a water sprinkler. A number of studies have been conducted on the effect of a water sprinkler spray on pool fires [Kokkala, 1992; Han et al., 1997; Kim et al., 1997]. In their flame suppression studies of liquid pool fires using overhead water sprays, flame-enhancing behavior similar to the high momentum suppressant jet was also observed [Kokkala, 1992; Kim et al., 1997]. In these experiments, fire enhancement was attributed to increased mixing of fuel and air as a result of water interacting with the pool surface. Bench-top experiments with liquid water droplets falling onto the surface of a boiling hydrocarbon have also shown that splashing of the target liquid can occur depending on the impact Weber number of the incoming drop [Manzello and Yang, 2002]. 


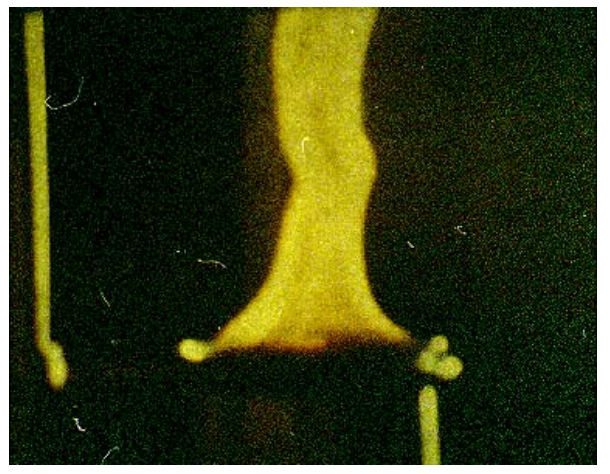

(a)

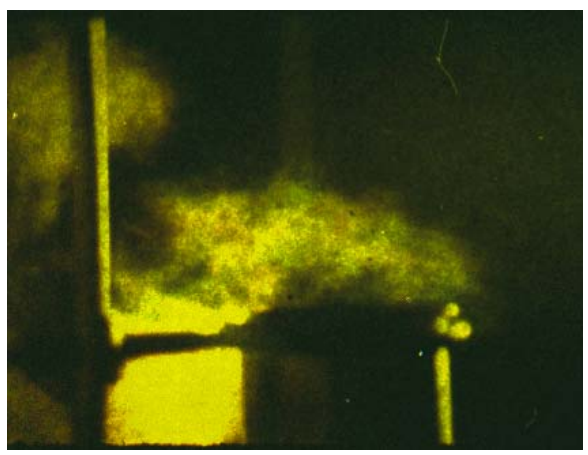

(c)

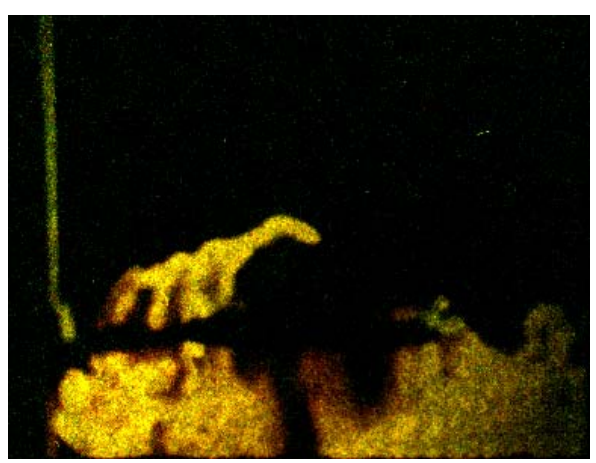

(e)

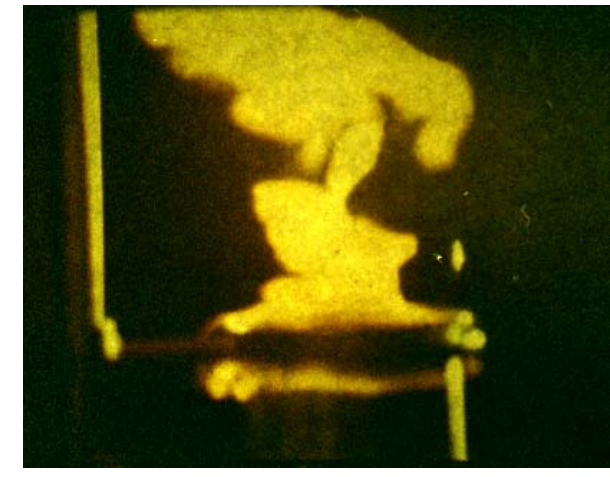

(b)

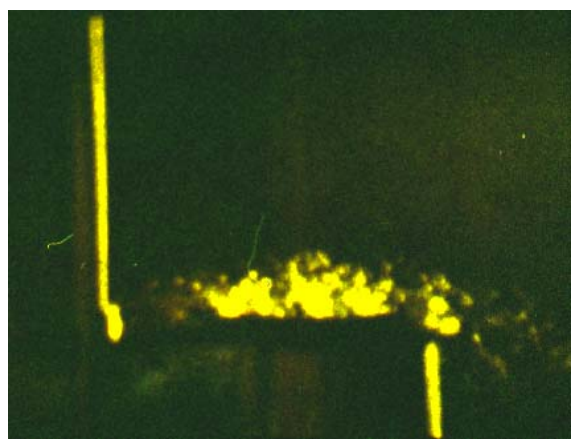

(d)

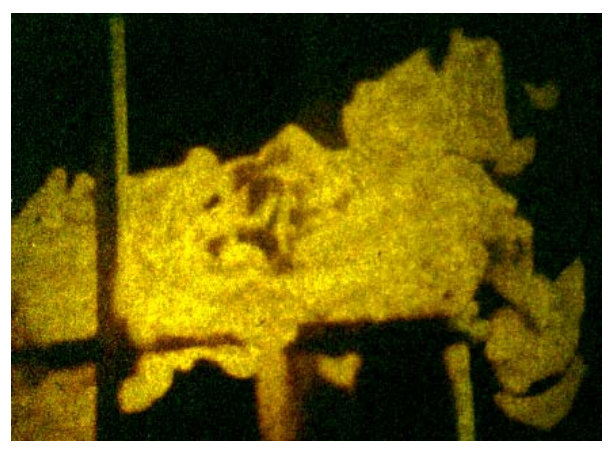

(f)

Figure 3. Response of a $10 \mathrm{~cm}$ heptane pool fire to a high pressure, overhead nitrogen release. 


\subsubsection{Flame Straining}

Rapid changes in the appearance of a flame such as its size or luminosity after suppressant discharge could be interpreted as enhanced or accelerated burning. Flame appearance including its shape and color is a natural consequence of the conditions that define the flow. Changes in the appearance of a flame may occur due to any number of factors including changes in the local instantaneous flows of fuel or air, or changes in the local pressure or temperature. Upon suppressant release, the flow field in a nacelle or dry bay may significantly change and the appearance of a fire may change as the local flows of fuel or air change. When suppressant delivery is complete, flowfield conditions may return to the previous state or could differ. If a flame experiences increased air flow, then the flame may undergo straining.

An unstrained hydrocarbon diffusion flame is typically luminous in appearance. As the flow into such a flame increases, the flame weakens, becoming shorter and blue in appearance. Subsequent decrease in the flow would alter the flame appearance again, elongating the flame length and changing its color to one that is luminous. An example of this phenomenon is exemplified in Fig. 4, which shows JP-8 spray flames [Hamins et al., 1996] under conditions of high and low air flow, all other conditions being the same. The high air flow case represents near-extinction conditions and the flames are shorter and bluish. The low air flow case is much longer and the flames are more luminous, which would give rise to a relatively higher radiative heat flux.
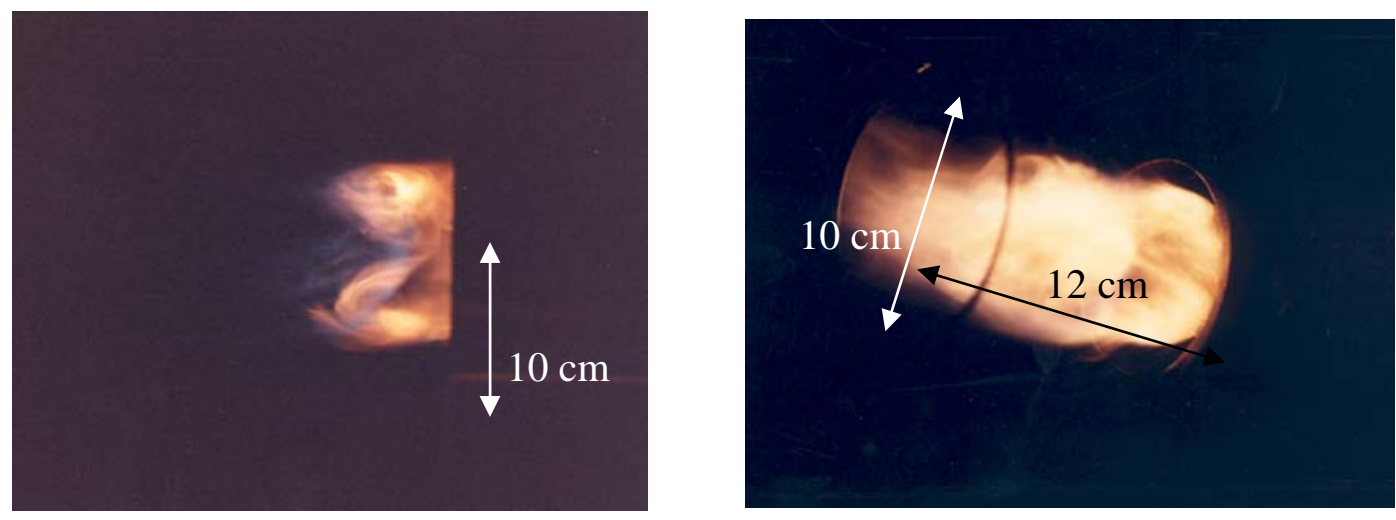

Figure 4. Baffle stabilized JP-8 spray flames in a wind tunnel under conditions of approximately $10 \mathrm{~m} / \mathrm{s}$ air flow (left) and $2 \mathrm{~m} / \mathrm{s}$ air flow (right). 


\subsubsection{Mixing}

The nature and rate of reactant mixing plays a role in the burning rate of a fire. This is true for both premixed and non-premixed flames. The discussion here is focused on non-premixed flames, since most actual fires are non-premixed by nature. A nonpremixed flame is reactant-limited by definition. A ventilation-limited fire is one type of reactant-limited fire, where the transport of air to the reaction zone limits the burning rate. A fuel-limited fire is another type of reactant-limited fire. It is defined by overventilated conditions and the transport of fuel to the reaction zone limits the burning rate. Transport of reactants to a fire can certainly be affected by agent delivery. This can happen in one of several ways. Air can be entrained into the flow of a suppressant or pushed ahead of a suppressant jet. Alternatively, a fuel leak in the form of a spray, for example, could be displaced or disrupted by a suppressant jet. Each of these scenarios is possible. Reactant delivery can also impact turbulence levels, which can impact heat transfer and burning rates. The impact of agent induced mixing on a fire will be dependent on the details of each of these scenarios and will depend on the specifics of the geometric configuration, the flowfield, and agent effectiveness. Air entrainment into the centerline of axisymmetric jets was previously studied for steady state flows [Pitts, 1991]. There is no information on entrainment in unsteady jets, or on the transient flow of air pushed just ahead of an instantaneous flow of a jet. In addition, these issues were not investigated in the context of a suppressant flow and the effect of entrainment on fire suppression.

\subsubsection{Heat transfer and Chemistry related effects}

Unwanted enhanced burning after suppressant delivery may occur through heat transfer related effects. Heat transfer effects may include re-ignition and/or flame stabilization that can occur due to preheating of a solid object that acts like a flame anchor or ignition source. There are no known studies on the effect of a suppressant discharge on fire heat transfer. Yet, it is conceivable that the suppressant discharge could tilt a fire and promote heat transfer to a solid object such as a metal bulkhead or flange. Such a situation could enhance flame stability. Subsequent heating of such an item could promote re-ignition and flame stabilization, enhancing flame stability. 
Addition of the some types of suppressants can alter the flame chemistry and impact soot levels. For example, the chemically active suppressant $\mathrm{CF}_{3} \mathrm{Br}$ can enhance the concentration of soot in a hydrocarbon diffusion flame [Smyth and Everest, 1996]. This was demonstrated in both laminar and turbulent diffusion flames. Enhanced soot levels lead to increased radiative heat transfer, which is a key mechanism of fire spread and growth.

Some suppressants can be considered to be fuels as they are exothermic. For example, halogenated fire suppressants release enthalpy, albeit relatively small, when introduced into a hydrocarbon flame. This can lead to larger visible flame volumes, for example a $6 \%$ volume fraction of $\mathrm{CF}_{3} \mathrm{Br}$ in an ambient temperature oxidizer stream has an adiabatic equilibrium temperature of $600 \mathrm{~K}$. There are some studies in the literature on the chemical effects of a suppressant. Holmstedt and Anderson [1993] and Holmstedt et al. [1994] measured the heat release rate using oxygen consumption calorimetry for various suppressants added to propane/air diffusion flames. Some agents were found to increase the heat release rate by almost a factor of four. As the heat release rate of a fire increases, the flame volume may be expected to increase and the appearance of a fire may suddenly become very large with application of such a suppressant.

\subsection{Assessment of Background Information}

The background information attained through interviews and the literature review indicates that a multiplicity of mechanisms may be relevant to an understanding of unwanted burning after suppressant delivery. These include flowfield-related effects, heat transfer effects, chemical effects, and enhanced mixing effects. It is often difficult to categorize these mechanisms in a simple manner because the physics are complex and the mechanisms are often coupled. Each of these effects may have an impact on flame volume or the appearance of a fire and on fire suppression requirements. Consideration of the background information, however, suggests that the main hazard associated with unwanted accelerated burning after suppressant delivery is system over-pressurization. Whereas changes in flame appearance or flame volume are not necessarily hazardous, system over-pressurization, on the other hand, could lead to structural damage of an aircraft. 
In an effort to better understand the hazards associated with the phenomena of unwanted accelerated burning, the next portion of this report analyzes three cases that exhibit system over-pressurization or pressure fluctuations after suppressant delivery.

\section{Case Studies}

Section 4.1 of this report identified a number of full-scale experimental facilities in which unwanted accelerated burning after suppressant release appears to be hazardous. In those cases, over-pressure led to the destruction or the potential for destruction of the experimental facilities. In this section, the most hazardous cases are further analyzed in an effort to understand the basis for the unwanted accelerated burning after suppressant release.

\subsection{Case 1: Analysis of Over-Pressurization during Suppression in the NRL Moderate-}

\section{$\underline{\text { Scale Enclosure }}$}

Through a series of carefully crafted experiments, Maranghides and Sheinson [2000] at NRL documented that suppressant discharge in a moderate-scale enclosure $\left(28 \mathrm{~m}^{3}\right)$ can cause significant fire flare-up and pressure increases for unconfined volatile liquid fuels in the presence of a hot ignition source. The experiments were conducted to evaluate the performance of various suppression technologies for use in flammable liquid storage rooms on-board Navy vessels. This section of the report summarizes their experimental findings, which were reported previously [Maranghides and Sheinson, 2000] and then analyzes the experimental results.

The suppression experiments are first described. Two types of fires burned simultaneously. The first consisted of a burning liquid fuel that flowed in a cascading manner over shelving filled with $20 \mathrm{~L}$ buckets simulating storage containers to be found shipboard. To control fuel delivery, the buckets were sealed and empty, and fuel associated with the cascading fire was metered. The fire was three-dimensional in nature and was obstructed from direct suppressant impingement. A burning fuel-filled rectangular pan ( $0.3 \mathrm{~m}$ x $0.3 \mathrm{~m})$ was also used. The fuel was composed of $80 \%$ methanol and $20 \%$ heptane (by volume). Methanol was selected because it is a 
shipboard material that presents a difficult extinguishment challenge and the heptane was included to make the flames visible for safety purposes.

The fire was allowed to burn for $20 \mathrm{~s}$ before the suppressant was delivered. The experiments used agent discharge cylinders filled with HFC-227ea (1,1,1,2,3,3,3Heptafluoropropane or FM-200) pressurized with $\mathrm{N}_{2}$ to $4.1 \mathrm{MPa}$, which required approximately $1 \mathrm{~kg}$ of nitrogen. The nozzle used for the tests had a $1 \mathrm{~cm}$ diameter and was located overhead in the center of the compartment and oriented downwards with its four outlets oriented in the cardinal directions $\left(0^{\circ}, 90^{\circ}, 180^{\circ}, 270^{\circ}\right)$. Suppressant discharge times were roughly $10 \mathrm{~s}$.

Figures 5a-c show the NRL fire suppression test facility from exterior and interior views. The exterior view (Fig. 5a) shows that the enclosure wall is fitted with four large $\left(0.36 \mathrm{~m}^{2}\right)$ explosion relief panels. The first interior view (Fig. $\left.5 \mathrm{~b}\right)$ was taken through the door shown in (Fig. 5a). The photo shows the three-dimensional pan fire with cascading, burning liquid fuel. The fuel in this case was heptane, a volatile liquid. Figure $5 \mathrm{c}$ is an image captured from a video camera viewing the enclosure interior. The reddish glow is identified as a deflagration and appears as a radiating volume of combusting gas. This image was taken just before the explosion panels in Fig. 5a ruptured due to the large rapid pressure increase within the enclosure.

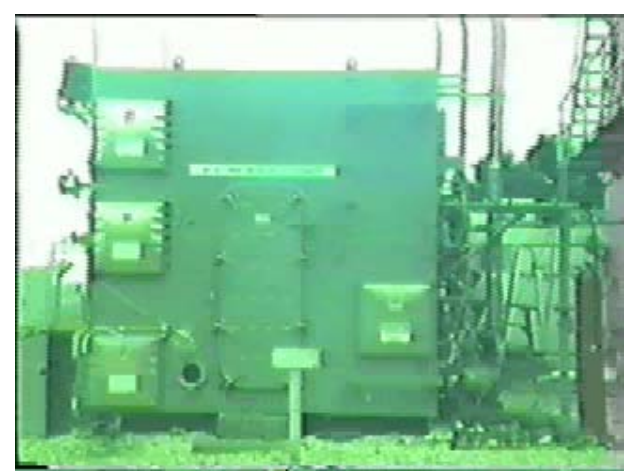

(a)

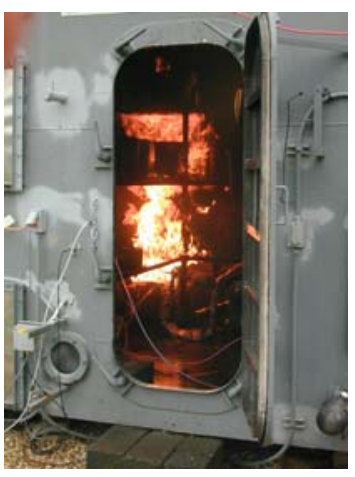

(b)

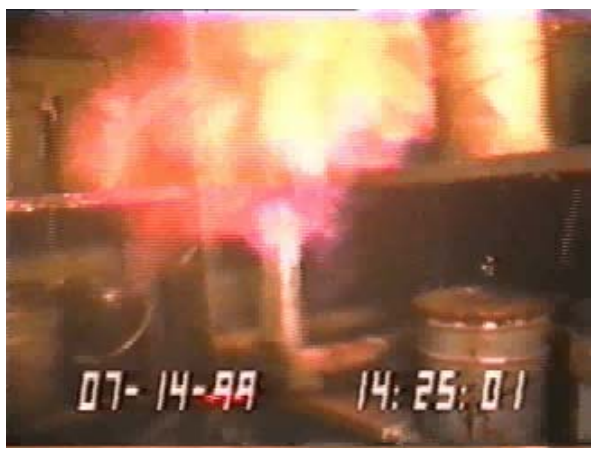

(c)

Figure 5. (a) Exterior view of the moderate-scale $\left(28 \mathrm{~m}^{3}\right)$ NRL enclosure; (b) Interior view of the NRL enclosure with an obstructed, cascading three-dimensional pan fire; (c) deflagration wave propagating within the enclosure. 
Typical measurements of the transient pressure within the NRL enclosure during the suppression experiments are shown in Figs. 6 and 7 [Sheinson and Maranghides, 2002]. The suppressant mass discharged during the experiments was designed such that the suppressant volume fraction in the enclosure was equal to $9.1 \%$ and $11.5 \%$ for the conditions reported in Figs. 6 and 7, respectively. These values are equal to the cup burner volume fractions times a factor of 1.1 and 1.4, respectively. (The critical cup burner volume fraction for the methanol/heptane mixture was measured to be $8.3 \%$ [Maranghides and Sheinson, 2000].)

The experimental compartment was sealed during the experiments. As the fire heated the enclosure, the pressure was observed to increase. Figures 6 and 7 show that the pressure increased steadily after ignition. Experiments proceeded with $20 \mathrm{~s}$ of burning before initiation of the discharge of the HFC-227ea suppressant. The pressure in the enclosure (see Figs. 6 and 7) decreased rapidly as the compressed liquid agent vaporized, absorbing heat from within the compartment. This led to rapid cooling of the compartment and a consequent immediate decrease in the pressure. The cooling effect is quite large considering that the pressure drop occurs despite a significant amount of suppressant mass being added to the compartment. The temperature data (not shown) from these experiments are consistent with this interpretation.

Figure 6 shows a rapid pressure rise shortly after the suppressant discharge. After the initial cooling effect, the suppressant in the compartment quickly expands, creating a pressure increase in the compartment. At time zero in Fig. 6, the suppressant was deployed and the fire was not extinguished by the suppressant discharge. During the suppressant discharge, cascading fuel continued to flow into the compartment. A portion of this fuel was consumed by the fire. A fraction of the fuel, however, was unburned and vaporized during the suppressant discharge process. The vaporized fuel mixed with air, leading to rapid combustion in the form of a deflagration wave. These factors led to a pressure increase of approximately $13 \mathrm{kPa}$, causing rupture of the explosion panels. Through analysis of the video records, the experimental results indicated that suppressant delivery caused intensification of the fire and an increase in the burning volume. Maranghides and Sheinson [2000] suggest that the suppressant discharge increased fuel evaporation, leading to increases in the fuel burning area associated with the cascading 
fire. The pressure measurements in concert with the video record suggest that a combustion/deflagration wave developed in the enclosure. It should be noted that a hot ignition source $\left(\approx 550^{\circ} \mathrm{C}\right.$ ) was present throughout the experiments. The deflagration could have been initiated by the ignition source or by an unsuppressed kernel of the fire.

Other experiments at NRL showed that the pressure increase from the suppressant discharge alone (without the presence of the fire) did not cause the explosion panels to rupture. Experiments with a fire alone (no suppressant discharge) did not cause the explosion panels to rupture. In that case, the fire leveled-off at approximately $5.3 \mathrm{kPa}$ almost $30 \mathrm{~s}$ after fire initiation and the fire self-extinguished in the closed compartment after $75 \mathrm{~s}$.

Figure 7 represents a fire that was identical to that corresponding to the fire associated with Fig. 6 except that the suppressant mass was approximately $40 \%$ greater. The fire in Fig. 7 was extinguished by the suppressant discharge. The pressure trace in Fig. 7 was similar to Fig. 6 until the agent was released. At that time, the pressure rapidly decreased until its value reached the baseline. At that time, the video record shows that the fire was extinguished and no deflagration wave was observed.

In previous tests, rapid over-pressurization was observed to occur for a variety of suppressant types including gaseous, compressed liquid, and hybrid suppressants composed of liquid-phase plus dry powder. The results suggest that a combustible (premixed) fuel-air mixture can propagate when complete extinguishment does not occur and suppressant inertion volume fractions are not reached. The inertion volume fraction of HFC-227ea in a fuel mixture of $80 \%$ methanol plus $20 \%$ heptane was never measured. However, the inertion volume fraction of HFC-227ea has been reported as $11 \%$ to $11.5 \%$ by Holmstedt et al. [1994] in a propane/air mixture. Experiments were conducted in an $8 \mathrm{~L}$ vacuum tight cube fitted with an ignition electrode. Using the same device, Holmstedt et al. [1994] measured the inertion volume fraction of Halon 1301 to be $6.5 \%$ by volume in agreement with Hamins et al. [1994]. The effects of ignition energy and enclosure size were shown to impact the results.

Flames burning methanol are expected to be more difficult to extinguish. The fuel of interest, however, is a $20 \%$ methanol plus $80 \%$ heptane mixture (by volume). Macek [1974] shows that as alcohols become less oxygenated, the temperature limits resemble 
pure hydrocarbons. Calculations using the NASA CEC program [Gordon and McBride, 1976] of the limiting volume fraction in a heptane/air mixture based on a critical temperature criteria for flammability limits [Macek, 1974] yields the same inertion volume fraction as a propane/air mixture. Therefore, the $11 \%$ value is considered a rough estimate of the inertion volume fraction for HFC-227ea in the methanol/heptane fuel mixture.

In Figs. 6 and 7, the suppressant volume fractions of $9.1 \%$ and $11.5 \%$ of HFC227ea were insufficient and sufficient, respectively, to extinguish the fires and prevent reignition. These results are consistent with the $11 \%$ inertion requirements discussed above. The situation is complicated by a number of factors. First, it is probably safe to assume that suppressant mixing was not homogeneous throughout the enclosure. Second, the HFC-227ea flammability data in this case (and typically) is for reactant mixtures initially at ambient temperature. Flammability limits, however, are temperature dependent and regions of the fires associated with Figs. 6 and 7 were preheated by the fires. These facts suggest that more information is needed to make definitive conclusions regarding the NRL experiments.

A separate series of experiments were conducted with a 2 min preburn duration and compartment ventilation turned off 30 s preceding agent discharge. The $\mathrm{O}_{2}$ depletion and $\mathrm{CO}_{2}$ generation during these experiments weakened the fires, significantly enhancing the performance of the fire suppressant and resulting in very rapid fire extinguishment. No over-pressurization or deflagrations were observed under these conditions. 


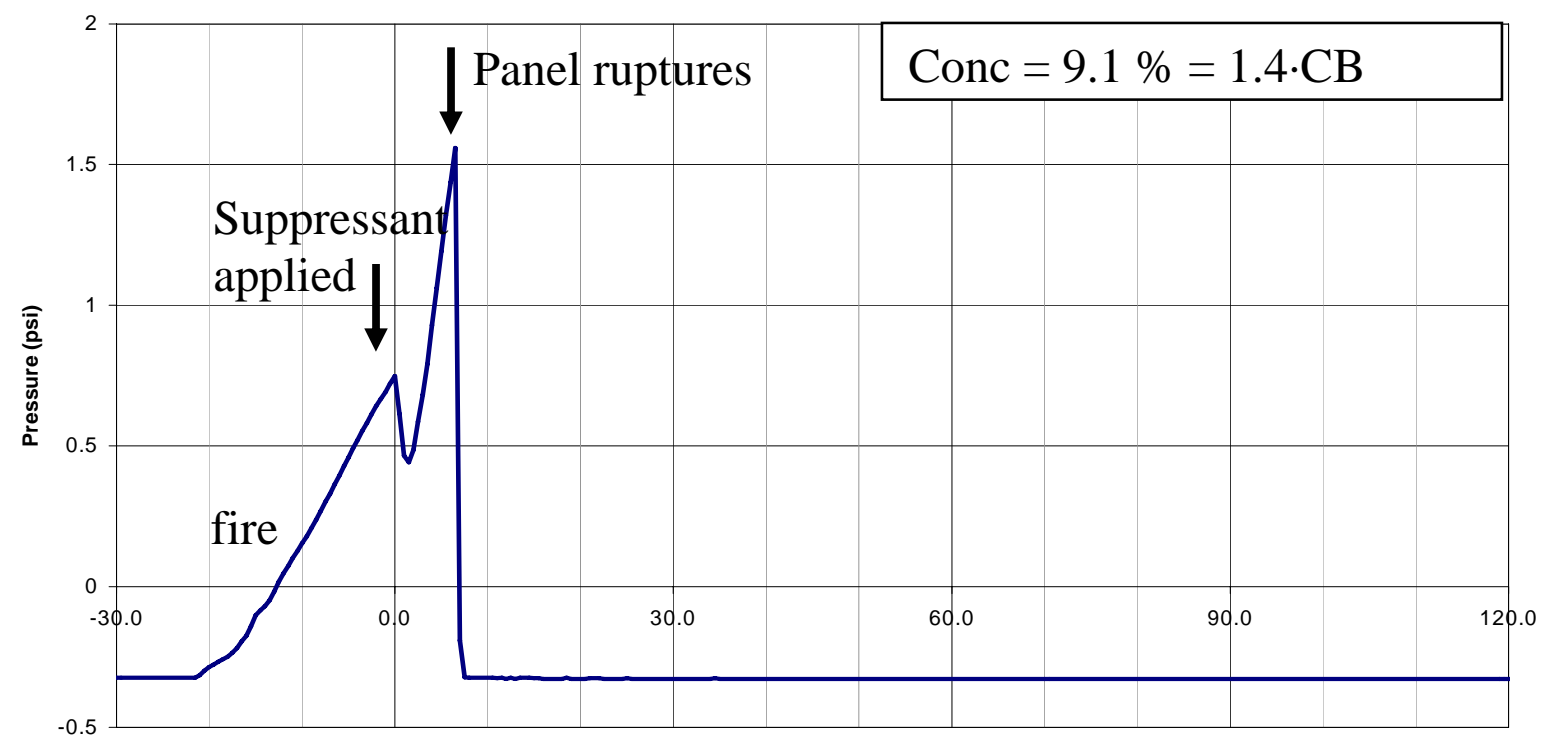

Time (s)

Figure 6. NRL fire suppression test results for FM-200 delivery onto the obstructed, cascading 3D/pan fire in the moderate scale enclosure $\left(28 \mathrm{~m}^{3}\right)$ with a design volume fraction of $9.1 \%$, which is equal to the cup burner volume fraction (CB) $+10 \%$.

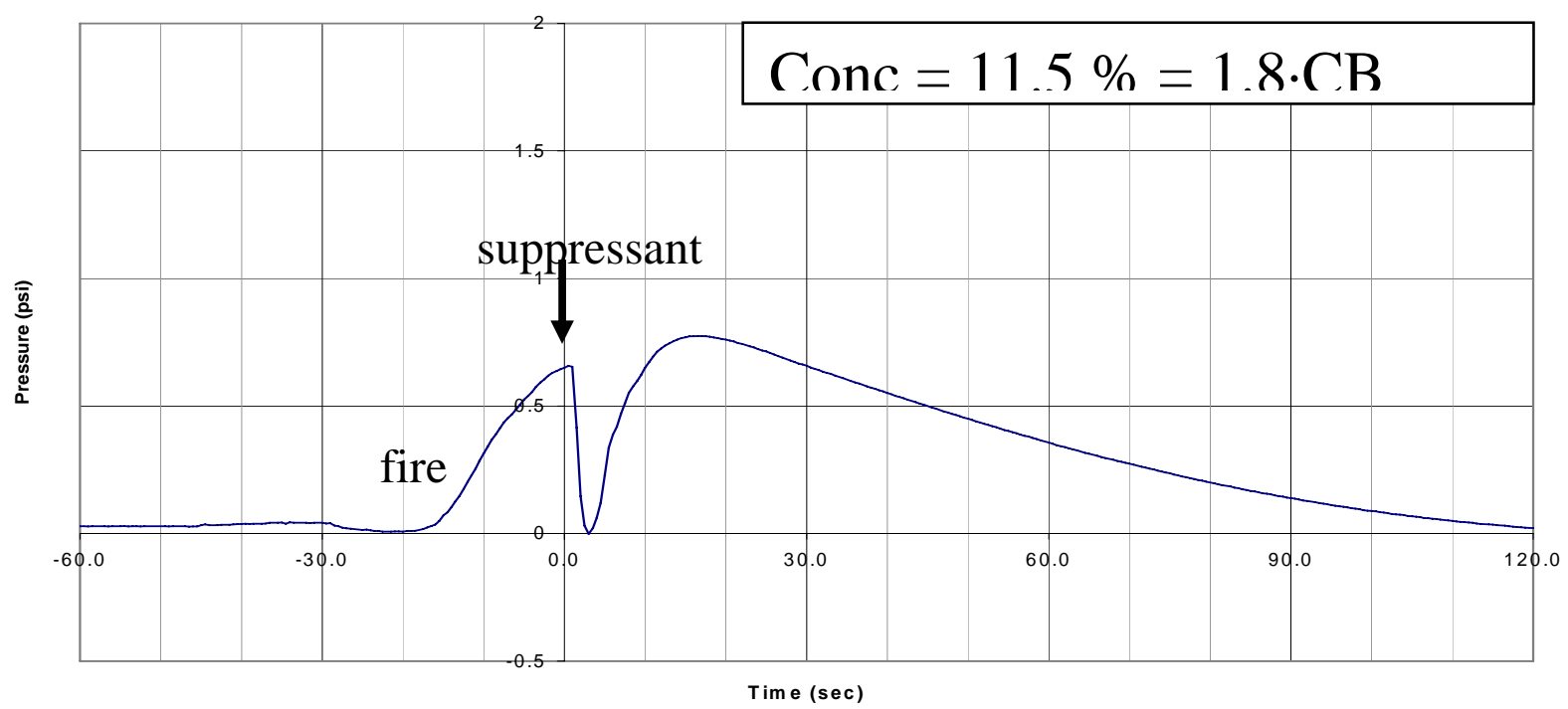

Figure 7. NRL fire suppression test results for FM-200 delivery an obstructed, cascading 3D/pan fire in a moderate scale enclosure $\left(28 \mathrm{~m}^{3}\right)$ with a design volume fraction of $11.5 \%$, which is equal to the cup burner volume fraction (CB) $+40 \%$. The fire was extinguished and the pressure panels did not blow-out. 


\section{2 Case 2: Modeling of Global Properties during Fire Suppression in a Dry Bay}

\subsubsection{Background}

An unanticipated catastrophic event occurred during real-scale fire suppression testing on August 28, 1998 at the C-130 VRP Phase IA-Wing Leading Edge Dry Bay Fire Extinguishing Agent Evaluation Baseline test (WLE-R-B-07), which was conducted in the Aircraft Survivability Research Facility Upper Range 3. This was the seventh and final baseline test on a replica C130H WLE dry bay test article containing $\approx 1000 \mathrm{~L}$ of JP8. In that incident, over-pressurization destroyed the full-scale test fixture. Six tests previous to the catastrophic event using $\mathrm{N}_{2}$-pressurized HFC-125 had led to routine suppression results. The seventh test was designed to investigate the impact of the $\mathrm{N}_{2}$ used for pressurization on the fire. It should also be noted that many hundreds, if not thousands, of suppression experiments were conducted in the Wright Patterson Dry Bay facilities without the occurrence of catastrophic over-pressurization. This included experiments in which suppressant delivery either extinguished or did not extinguish the test fire.

Dry bays are structural elements that are typically located in landing gear wheel wells, wing leading edges, munition bays, avionics equipment bays, and the fuselage of military aircraft. Dry bays vary considerably in their geometry, size, and ventilation, and have been described as void volumes within the mold line of an airplane, excluding air inlets, engine compartments, and exhaust nozzles [Bennett, 2002]. Dry bays normally contain electrical and mechanical components such as electrical cables, flight control actuators, hydraulic accumulators, and liquid oxygen containers. They are often adjacent to fuel tanks and may have fuel, hydraulic, coolant, and/or lubricating fluid lines passing through them. During normal operating conditions, dry bays are free of flammable liquids and vapors. During combat or equipment failure, however, flammable liquids may be released, leading to the possibility of a fire. 


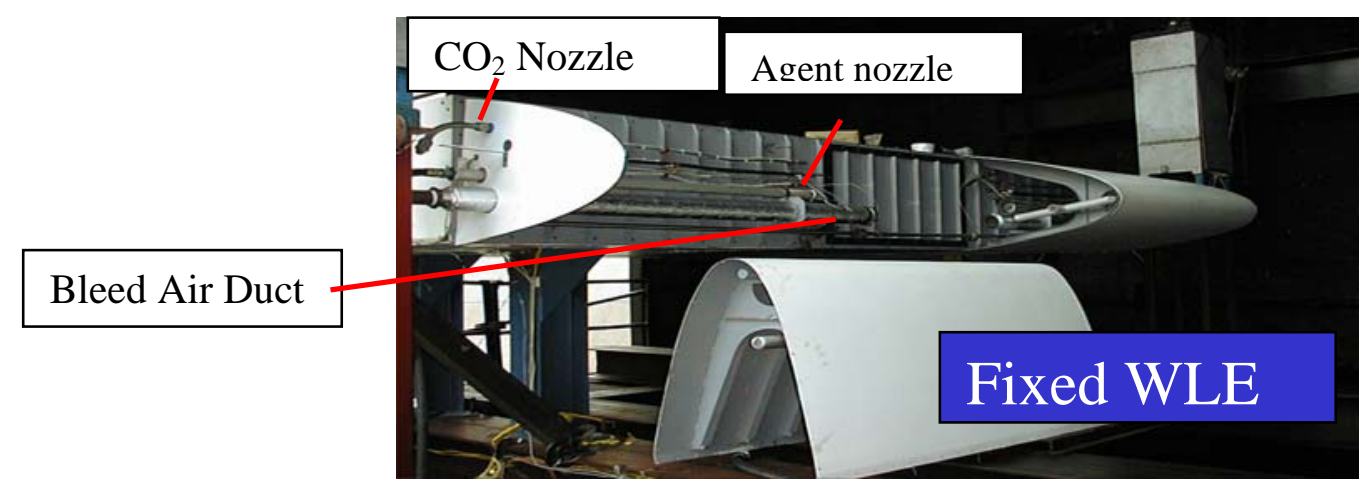

Figure 8. Photograph showing the inside of the Fixed Wing Leading Edge (WLE) C-130 Dry Bay Test Fixture with agent nozzle.

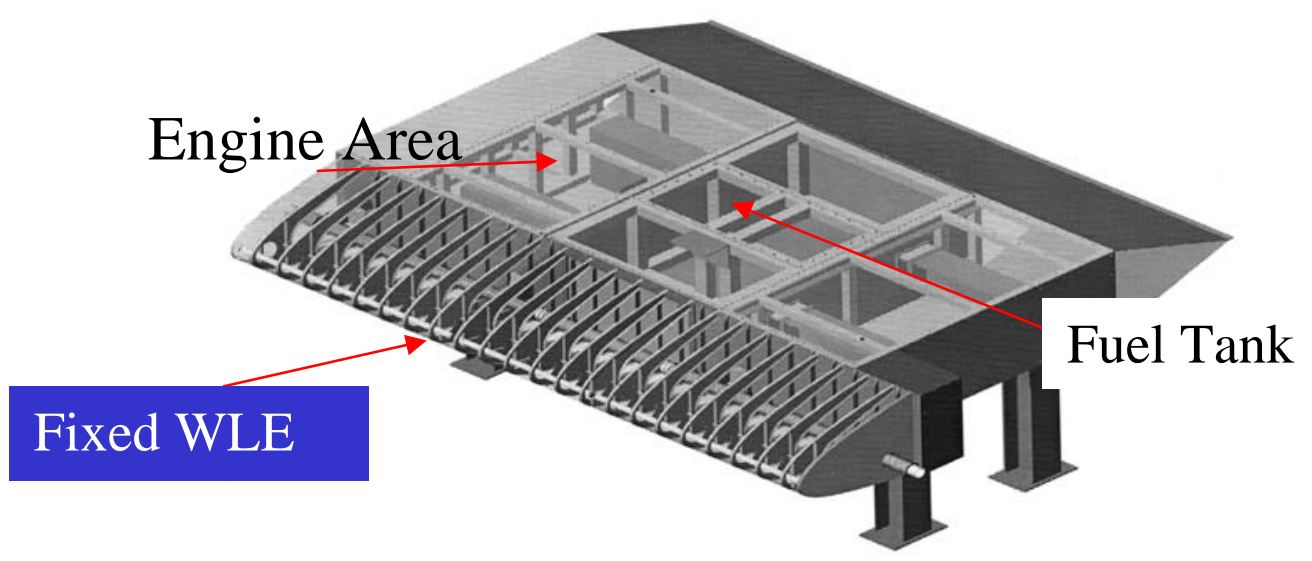

Figure 9. Drawing of the Fixed Wing Leading Edge (WLE) C-130 Dry Bay Test Fixture including the engine area and fuel tank.

Dry bays are particularly vulnerable to fire when an anti-aircraft projectile ruptures a fuel tank or fluid line, necessitating rapid automatic detection and deployment of a suppressant in order to avoid aircraft loss. Full-scale fire suppression testing of dry bay fixtures has been conducted at a number of facilities in the U.S including the Wright Patterson Air Force Base, where an extensive experimental program has been conducted 
for many years. Testing was based on simulation of realistic operating conditions and "live" incendiary projectiles varying in size from $12.7 \mathrm{~mm}$ to $23 \mathrm{~mm}$. Figures 8 and 9 show the Fixed Wing Leading Edge C-130 Dry Bay Test Fixture including the agent nozzle, fuel tank and engine area.

The incident that occurred during real-scale fire suppression testing on August 28, 1998, which led to destruction of the Wright Patterson C-130 VRP Phase IA-Wing Leading Edge Dry Bay was unique. Because the reasons for the failure were unclear, an investigation was commissioned. The investigation reconstructed the experimental timeline and examined possible causes of the incident. The salient information in the investigation report included the following incident timeline:

1. a projectile penetrated the outer wall of the Dry bay (time $=0$ ).

2. The detection system was activated and the suppressant $\left(\mathrm{N}_{2}\right)$ deployed at $20 \mathrm{~ms}$.

3. At approximately $40 \mathrm{~ms}$, the agent was delivered into the fixture.

4. Approximately $0.1 \mathrm{~L}$ of nitrogen was discharged into the replica dry bay volume of $1500 \mathrm{~L}$.

5. The line leading from the agent bottle to the delivery location within the Dry bay was filled with air at ambient conditions.

6. The Dry bay failed at $110 \mathrm{~ms}$.

7. Fire/flames were observed at $166 \mathrm{~ms}$.

The rate of the pressure rise for the test was similar to previous tests. There was an initial short duration pressure rise of $30 \mathrm{kPa}$ due to the threat impact, a quick drop-off, then a ramping to the peak at $95 \mathrm{~ms}$. A rapid drop-off after the peak pressure occurred due to failure of the test article and subsequent venting. The investigation report concluded that the release of agent $\left(\mathrm{N}_{2}\right)$ in this case likely acted to mechanically agitate the air, which contributed to a vigorous and rapid combustion event that led to overpressurization and mechanical damage of the test apparatus.

This was a unique incident in terms of aircraft fire suppression testing. According to those who perform dry bay suppression testing, there are no other documented incidents of catastrophic failure of a real-scale suppression test facility. Conversations with those in the aircraft industry suggest that such failures are extremely rare or non- 
existent [Rosenfeld, 2002]. For these reasons, the C130 WLE Dry Bay incident provides a unique data point on the phenomena of unwanted accelerated burning after suppressant delivery. Probable cause of the incident merits attention.

The investigation report is classified, which precluded obtaining the report in its entirety [Haas, 2000; Cyphers, 1998]. From the sections of the report that were finally made available to NIST, no modeling of the incident was reported. Quantitative analysis was limited to use of the ideal gas law. In this study, modeling is used to gain insight into the nature of the phenomena. Detailed computational fluid dynamics (CFD) modeling of the C130 WLE Dry Bay suppression experiments, however, would be extremely complex due to the presence of a ballistic round, accompanying shock waves, fuel splashing (two phase flow), hydraulic ram, multiple ignition sources (hot shrapnel), and so on. Instead, a simplified analytic approach was taken to simulate the essential dynamics of the incident. That model is outlined below.

It should be noted that over-pressurization of the test apparatus was not unusual. According to measurements made during the experiment, failure of the C130 dry bay fixture occurred when the pressure inside of the apparatus reached $54 \mathrm{kPa}$. The apparatus had survived earlier experiments when the pressure had reached $30 \mathrm{kPa}$.

The experiment used an inert suppressant $\left(\mathrm{N}_{2}\right)$, but at a volume fraction that was $0.4 \%$ of the cup burner value, an amount that would have little impact on the stability of the fire and certainly would not extinguish the fire. To better understand the conditions in the dry bay during fire suppression, an analytic approach was taken to simulate the pressure in the enclosure. A numerical approach was not used due to the complexities mentioned above.

An Air Force investigation of the event concluded that "increased level of fluid ignition (combustion)" was the source of overpressure. Experimental peculiarities were noted including the use of a suppressant delivery line that was air-filled.

\subsubsection{Analytic Approach}

A simplified analytic approach is described below, which was used to simulate the essential dynamics of the global properties during fire suppression in the incident that 
occurred at the Dry Bay Test Facility at WPAFB on August 28, 1998. Background information on the incident was briefly described above.

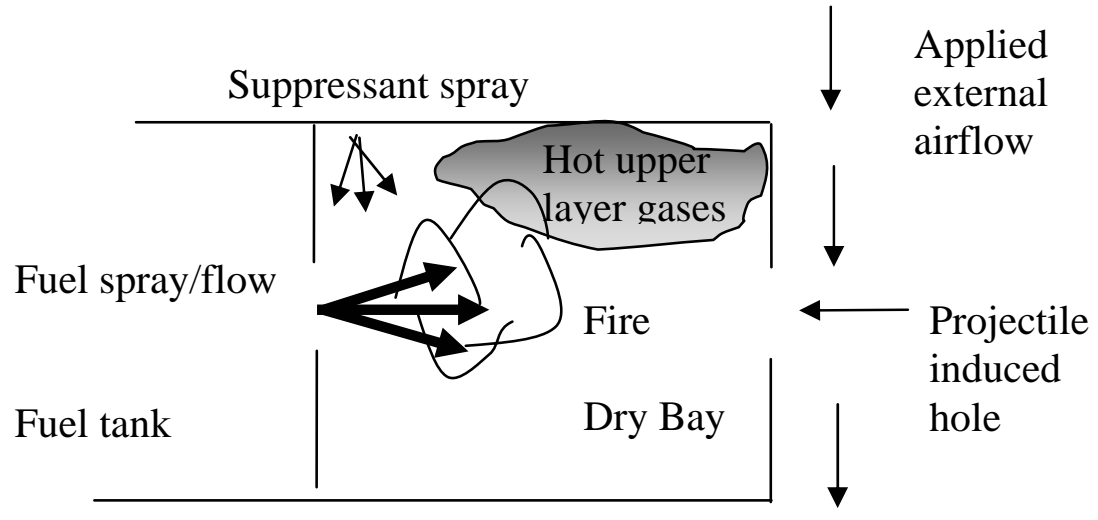

Figure 10. Fuel spray and fire resulting from projectile impact through the dry bay into the fuel tank.

In the experiments, a projectile penetrated the outer wall of the Dry bay (time $=0$ ) and then penetrated the fuel tank $(160000 \mathrm{~L})$, causing a flow and spray of jet fuel. The volume of the dry bay was $\approx 3 \mathrm{~m}^{3}$. Hot shrapnel rapidly ignited the fuel. Figure 10 schematically shows the fuel spray and fire resulting from impact of the projectile. Within a few milliseconds, an automatic detection system activated the suppression system, which delivered agent into the compartment at approximately $40 \mathrm{~ms}$. The static pressure transducer in the Dry bay peaked at $54 \mathrm{kPa}$ at $95 \mathrm{~ms}$. Almost immediately (10 ms later) the pressure in the Dry bay fell to ambient as the test compartment failed. The maximum pressure in other similar tests typically obtained $30 \mathrm{kPa}$ and compartment failure did not occur.

Using the formalism developed by Rehm and Forney (1992), the pressure in the dry bay during the fire suppression event is derived based on mass and energy conservation. Hydrodynamic ram associated with the projectile impact is not considered in this analysis. The basic premise of this simple type of fire model is that the enclosure can be divided into a small number of regions or zones with approximately uniform 
conditions. Zone models are widely used to understand the conditions in an enclosure during a fire. Zone models typically divide an enclosure into two control volumes, an upper layer of hot gas and smoke, and a lower layer of air.

The dry bay compartment in question was on the order of $1 \mathrm{~m}$ in length. In the experiments, a projectile strikes the external dry bay wall. At room temperature, the speed of sound in air is approximately $300 \mathrm{~m} / \mathrm{s}$, implying that the pressure in the dry bay equilibrates in a time on the order of $3 \mathrm{~ms}$. The timeline associated with the spray fire is thought to be on the order of $100 \mathrm{~ms}$, much longer than that required for equilibration of the compartment pressure, and allows application of the low Mach number form of the conservation equations. The equations that govern conservation of mass and energy are applicable even for the relatively rapid processes that occur in the situation of interest.

The gas in each layer has attributes of mass, internal energy, density, temperature and volume denoted respectively by $\mathrm{m}_{\mathrm{i}}, \mathrm{E}_{\mathrm{i}}, \rho_{\mathrm{i}}, \mathrm{T}_{\mathrm{i}}$, and $\mathrm{V}_{\mathrm{i}}$ where $\mathrm{i}=\mathrm{L}$ in the lower layer and $\mathrm{i}=\mathrm{U}$ in the upper layer (see Fig. 10). The compartment as a whole has the attribute of a single pressure $\mathrm{P}$. These eleven variables are related by the following constraints:

$$
\begin{aligned}
& \rho_{\mathrm{i}}=\mathrm{m}_{\mathrm{i}} / \mathrm{V}_{\mathrm{i}} \\
& \mathrm{E}_{\mathrm{i}}=\mathrm{c}_{\mathrm{v}} \mathrm{m}_{\mathrm{i}} \mathrm{T}_{\mathrm{i}} \\
& \mathrm{P}=\mathrm{R} \rho_{\mathrm{i}} \mathrm{T}_{\mathrm{i}} \\
& \mathrm{V}=\mathrm{V}_{\mathrm{L}}+\mathrm{V}_{\mathrm{U}}
\end{aligned}
$$

Equations 1-4 represent the definitions of density, internal energy of a gas, the ideal gas law, and the total volume. The specific heats at constant volume and constant pressure are related to the universal gas constant $\mathrm{R}$ by:

$$
\mathrm{R}=\mathrm{c}_{\mathrm{p}}-\mathrm{c}_{\mathrm{v}}
$$

The differential equations for mass in each layer are:

$$
\begin{aligned}
& \frac{\mathrm{dm}_{\mathrm{L}}}{\mathrm{dt}}=\dot{m}_{L} \\
& \frac{\mathrm{dm}_{\mathrm{U}}}{\mathrm{dt}}=\dot{m}_{U}
\end{aligned}
$$


The first law of thermodynamics states that the rate of increase of internal energy plus the rate at which the layer does work by expansion is equal to the rate at which enthalpy is added to the gas. The first law can be represented in differential form as:

$$
\frac{d E_{i}}{d t}+P \frac{d V_{i}}{d t}=\dot{q}_{i}
$$

A differential equation for the pressure can be determined by adding the upper and lower layer versions of Eq. 8 and noting that the change in volume of the upper and lower layers are related as:

$$
\frac{d V_{U}}{d t}=-\frac{d V_{L}}{d t}
$$

Equations 1-3 yield:

$$
\frac{\mathrm{dE}_{\mathrm{i}}}{\mathrm{dt}}=\frac{\mathrm{d}\left(\mathrm{c}_{\mathrm{v}} \mathrm{m}_{\mathrm{i}} \mathrm{T}_{\mathrm{i}}\right)}{\mathrm{V}}=\frac{c_{v}}{R} \frac{d\left(P V_{i}\right)}{d t}
$$

This leads to an equation for the time varying pressure P:

$$
\frac{\mathrm{dP}}{\mathrm{dt}}=\frac{(\gamma-1)}{\mathrm{V}}\left(\dot{\mathrm{q}}_{\mathrm{L}}+\dot{\mathrm{q}}_{U}\right)
$$

Equation 11 can be rewritten in terms of the non-dimensional pressure $(\tilde{p})$ in the dry bay enclosure (relative to the ambient external pressure, $=\tilde{p}_{\text {enc }}-\tilde{p}_{\text {amb }}$ ) and nondimensional time $(\tilde{t})$ considering enthalpy sources and sinks. The parameter $\gamma$ represents the ratio of the specific heats $\left(\mathrm{C}_{\mathrm{p}} / \mathrm{C}_{\mathrm{v}}\right)$, which is taken as a constant equal to 1.4 , the value of $\gamma$ for air. This formulation includes the global effects of forced ventilation and suppressant addition and is similar to that derived by Rehm and Forney [1992b] for the time-dependent pressure:

$$
\frac{\mathrm{d} \tilde{\mathrm{p}}}{\mathrm{d} \tilde{\mathrm{t}}}=\frac{(\gamma-1)}{\mathrm{V}}\left(\dot{\mathrm{q}}_{\mathrm{f}}+\dot{\mathrm{q}}_{f v}+\dot{\mathrm{q}}_{\mathrm{s}}-\dot{\mathrm{q}}_{\mathrm{v}}\right)
$$

where $\mathrm{V}$ is the enclosure volume and $\dot{q}_{i}$ is the dimensionless sensible enthalpy addition to the compartment due to several source terms. The subscript "f” represents the fire, "fv" 
is the enthalpy addition to the compartment due to forced ventilation, "s" represents enthalpy addition due to suppressant deployment, and "v" is the enthalpy that is lost to the exterior by flow through a hole or vent caused by a projectile. A portion $(\approx 10 \%)$ of the pressure differential is due to the Venturi effect caused by airflow on the exterior of the dry bay, which tends to diminish the pressure in the enclosure.

The calculation yields two interesting results, namely, that only a small difference in $\dot{q}_{f}$ could have caused failure of the fixture and that paradoxically, the pressure rise is larger for smaller vent sizes (small diameter projectiles). The results are consistent with the idea that the $\mathrm{N}_{2}$ release caused an increased amount of mixing and a relatively small amount of enhanced burning. The small size of the hole caused by the projectile exacerbated the situation.

In the C130 WLE dry bay suppression experiments, flight conditions were simulated by blowing air on the outside of the fixture at high speeds, typically $130 \mathrm{~m} / \mathrm{s}$ (300 mph), to simulate in-flight conditions. In this case, the pressure differential must account for the Venturi effect, which increases the fluid flow through the vent, although this effect is relatively small. Solution of Eq. 12 allows calculation of the pressure in the dry bay for various vent sizes. For simplicity, the fire source and the suppressant enthalpy addition are taken as constants. The size of the effective "vent" is determined by the incoming projectile and will be at least as large as the diameter of the incoming projectile. In a real aircraft, the Venturi-related pressure difference across a projectile induced vent can vary significantly depending on flight elevation, air speed, wind conditions, and the orifice coefficient, which is related to the hole character.

In the incident of interest, forced ventilation was zero and the initial pressure, $\tilde{p}(\tilde{t}=0)$, in Eq. 12 was taken as equal to 0.1 to account for the pressure difference associated with a venturi induced pressure for a $130 \mathrm{~m} / \mathrm{s}$ wind (300 mph) blowing past the dry bay. The venturi effect tends to decrease the final pressure in the dry bay by a relatively small amount ( $<10 \%)$, depending on the flow rate. Figure 11 shows the solution to Eq. 12 for $\tilde{p}(\tilde{t}=0)=0.1$. The pressure obtains $90 \%$ of its steady value ( $\tilde{p}=0.9$ ) when $\tilde{t}=4$ and asymptotes to $\tilde{p}=1$ when $\tilde{t}=10$. 
In the case of the dry bay incident in question, little suppressant was deployed and $\dot{q}_{s}<<\dot{q}_{f}$ and forced ventilation ( $\left.\dot{q}_{f v}\right)$ was absent [Cyphers, 2002]. The pressure increase due to the suppressant delivery was less than $300 \mathrm{~Pa}(0.04$ psig). Solution of Eq. 12 for these conditions is shown in Fig. 12, which is plotted in dimensional units with $\dot{q}_{f}$ equal to the dimensional fire heat release rate. Figure 12 shows that the calculated steady state enclosure pressure is a function of the vent size (projectile hole diameter) and the fire heat release rate $\left(\dot{q}_{f}\right)$. For a larger fire size, the calculation results show that the pressure will be larger. The figure also shows that for a larger vent size, the final pressure in the enclosure

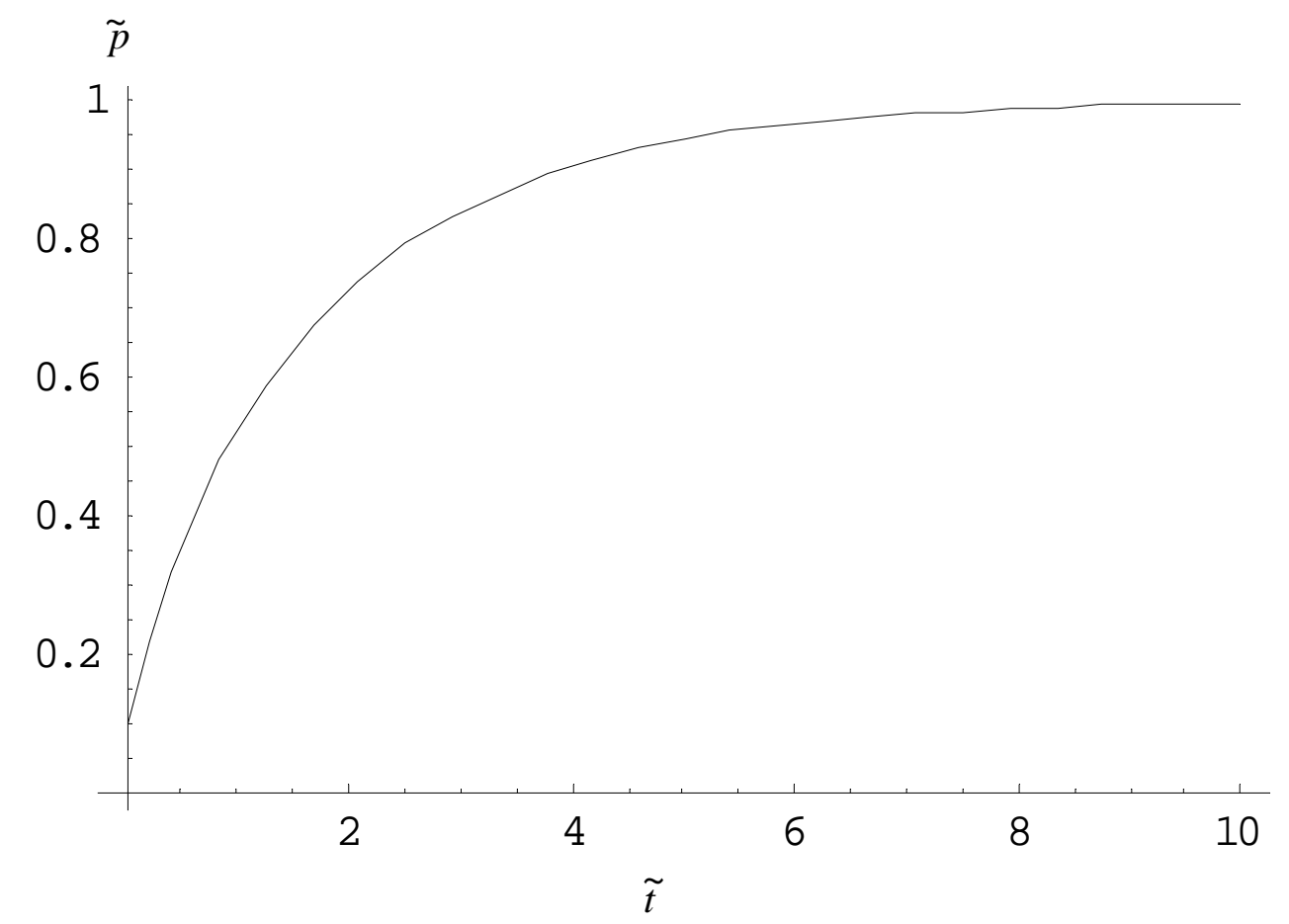

Figure 11. Solution of Eq. 12 for the pressure as a function of time in dimensionless units for initial conditions defined by $\tilde{p}(\tilde{t}=0)=0.1$. 


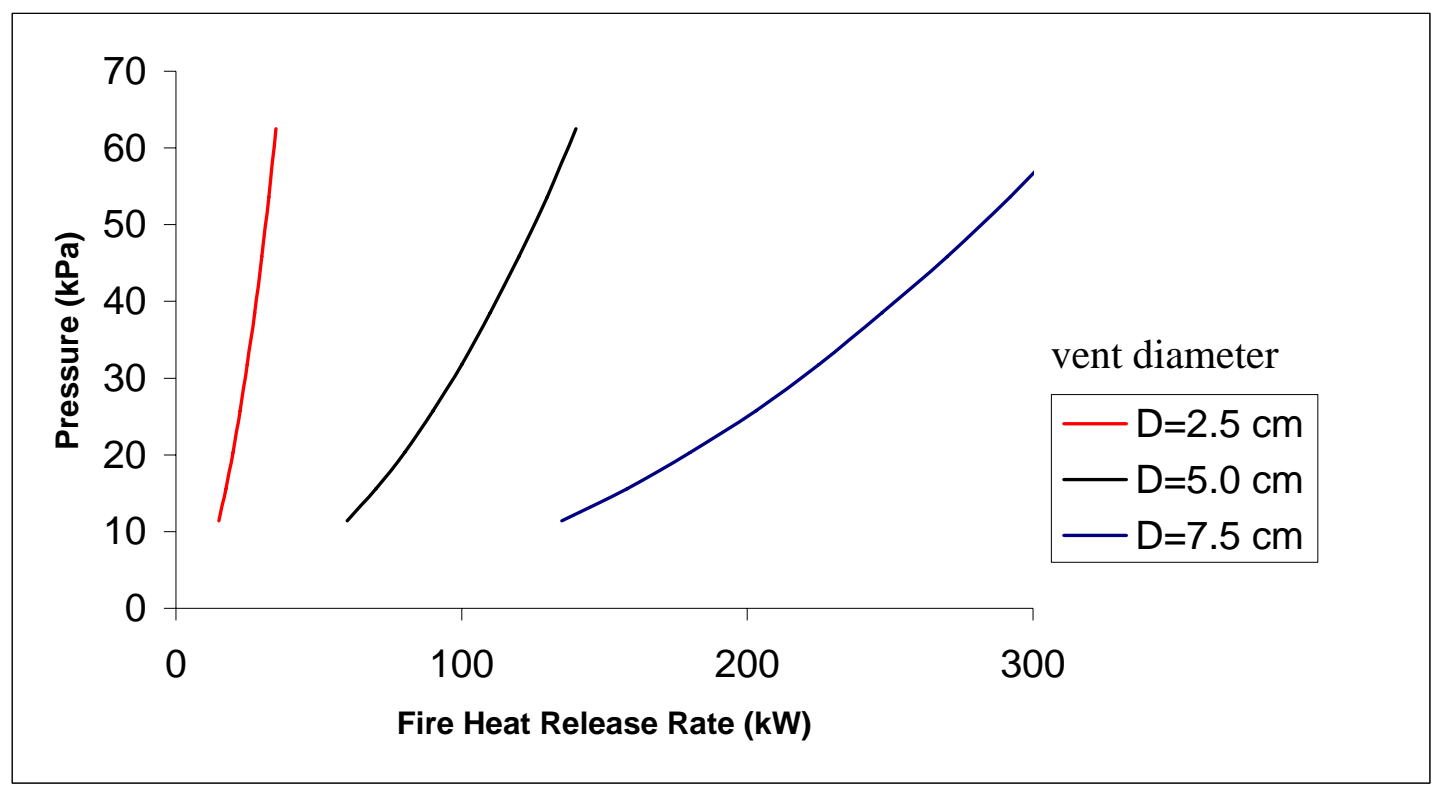

Figure 12. The calculated steady enclosure pressure as a function of the (dimensional) fire heat release rate $\left(\dot{q}_{f}\right)$ for various vent sizes.

is smaller. The enclosure pressure for small vent sizes is particularly sensitive to the fire size. The hole (assumed to be round) in the incident of interest was approximately $13 \mathrm{~cm}$ in diameter [Cyphers, 2002] and the critical pressure just before failure of the enclosure was $54 \mathrm{KPa}$ (7.8 psig). The enclosure in previous experiments reached pressures as high as $30 \mathrm{kPa}$ (4.3 psig) without catastrophic failure. Considering these parameters, solution of Eq. 12 leads to the results presented in Fig. 13, which shows the relationship between fire size and vent diameter for final enclosure pressures of $54 \mathrm{kPa}(7.8 \mathrm{psig})$ and $30 \mathrm{kPa}$ (4.3 psig). The figure shows that the difference in fire size $\left(\dot{q}_{f}\right)$ between these two pressures is roughly $25 \%$, the difference between $600 \mathrm{~kW}$ and $800 \mathrm{~kW}$ or $200 \mathrm{~kW}$. Thus, only a moderate difference in fire size could have caused pressurization sufficient to bring about failure of the test fixture. All other conditions being equal, Fig. 13 shows that paradoxically, a dangerous situation can arise in the instance of a smaller projectile hole size, which may lead to a smaller vent size. Of course, all other conditions may not be equal if the hole size differs.

The above calculations assumed that the time to reach steady pressure in the enclosure depends on the vent and fire sizes. This is not necessarily the case. Figure 14 
shows the calculated time to obtain a steady pressure in the enclosure ( $\tilde{t}=4$ in Fig. 11 ) as a function of hole size for fire with a $50 \mathrm{~kW}, 100 \mathrm{~kW}, 200 \mathrm{~kW}$, and $400 \mathrm{~kW}$ heat release rate. For a $100 \mathrm{~kW}$ fire and a $12.7 \mathrm{~cm}$ hole, steady pressure is achieved in $122 \mathrm{~ms}$. The time increases as the fire size increases and as the hole size decreases. In the incident in question, the pressure was measured to obtain a maximum $95 \mathrm{~ms}$ after projectile impact. The fire is assumed to have initiated at the time of projectile impact. This suggests that a steady state pressure was likely not obtained in the incident in question. The calculated fire sizes would therefore need to be larger than those shown in Fig. 12 to achieve the observed failure pressure after $95 \mathrm{~ms}$, but the difference between the fire size resulting in pressure failure and the fire size for the largest observed pressure when failure did not occur is approximately $25 \%$. This indicates that there is a fine line between safety and failure in terms of the critical fire size. The dry bay problem is complicated by the actual geometry in the dry bay, which was composed of two similar size enclosures connected by a relatively small duct (13 cm in diameter). A smaller effective dry bay volume would require a correspondingly smaller heat release rate to obtain the same enclosure pressures given the same heat release rate. Similarly, steady burning would take less time to achieve in a smaller enclosure volume.

Figure 15 shows the solution to Eq. 12, $95 \mathrm{~ms}$ after initiation of the fire for a vent size of $12.7 \mathrm{~cm}$ (5 in). The critical failure pressure of $54 \mathrm{kPa}$ (7.8 psig) is obtained for a steady 2.1 MW fire, whereas a pressure of $30 \mathrm{kPa}$ (4.3 psig) is obtained for a fire size of 1.5 MW, which is a difference of almost $25 \%$. 


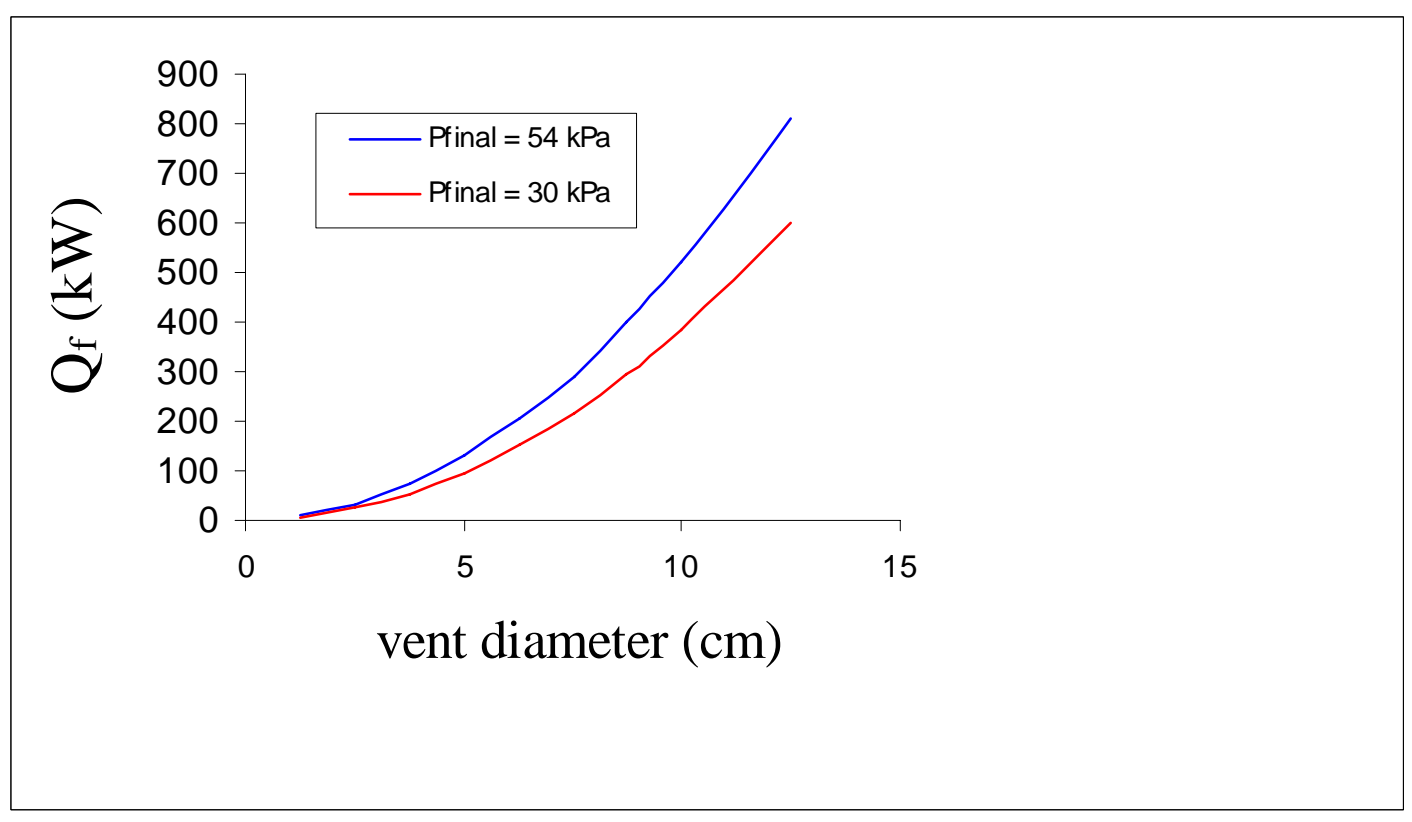

Figure 13. The fire heat release rate as a function of the vent hole diameter for steady pressures equal to $54 \mathrm{kPa}$ (7.8 psig) and $30 \mathrm{kPa}$ (4.3 psig).

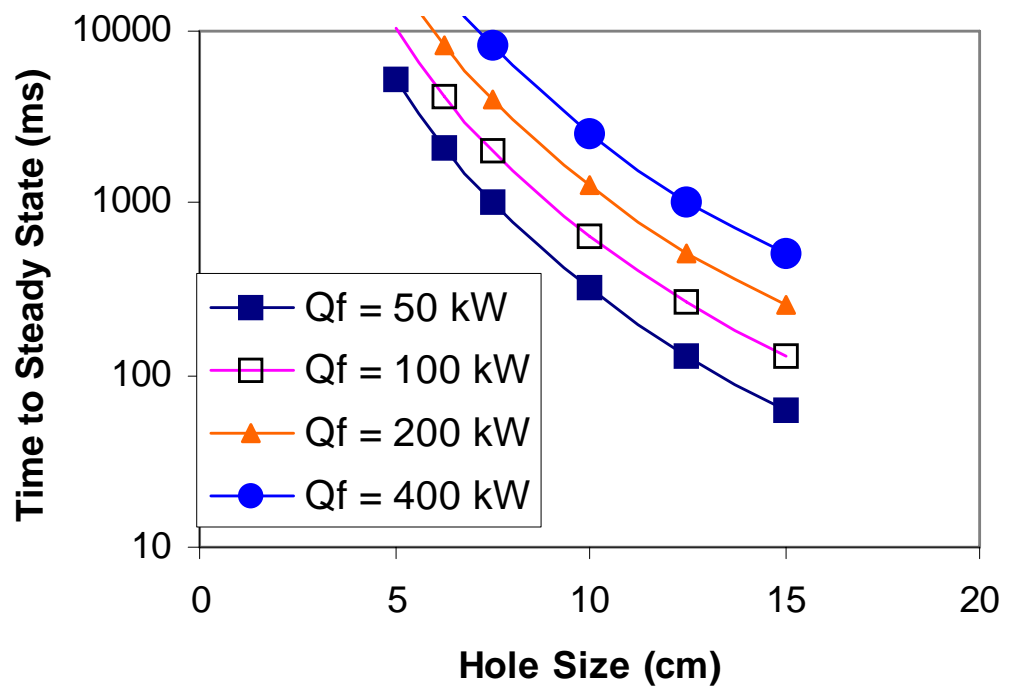

Figure 14. The calculated time to obtain a steady enclosure pressure $(\tilde{t}=4$ in Fig. 11) as a function of vent hole diameter for various fire heat release rates. 


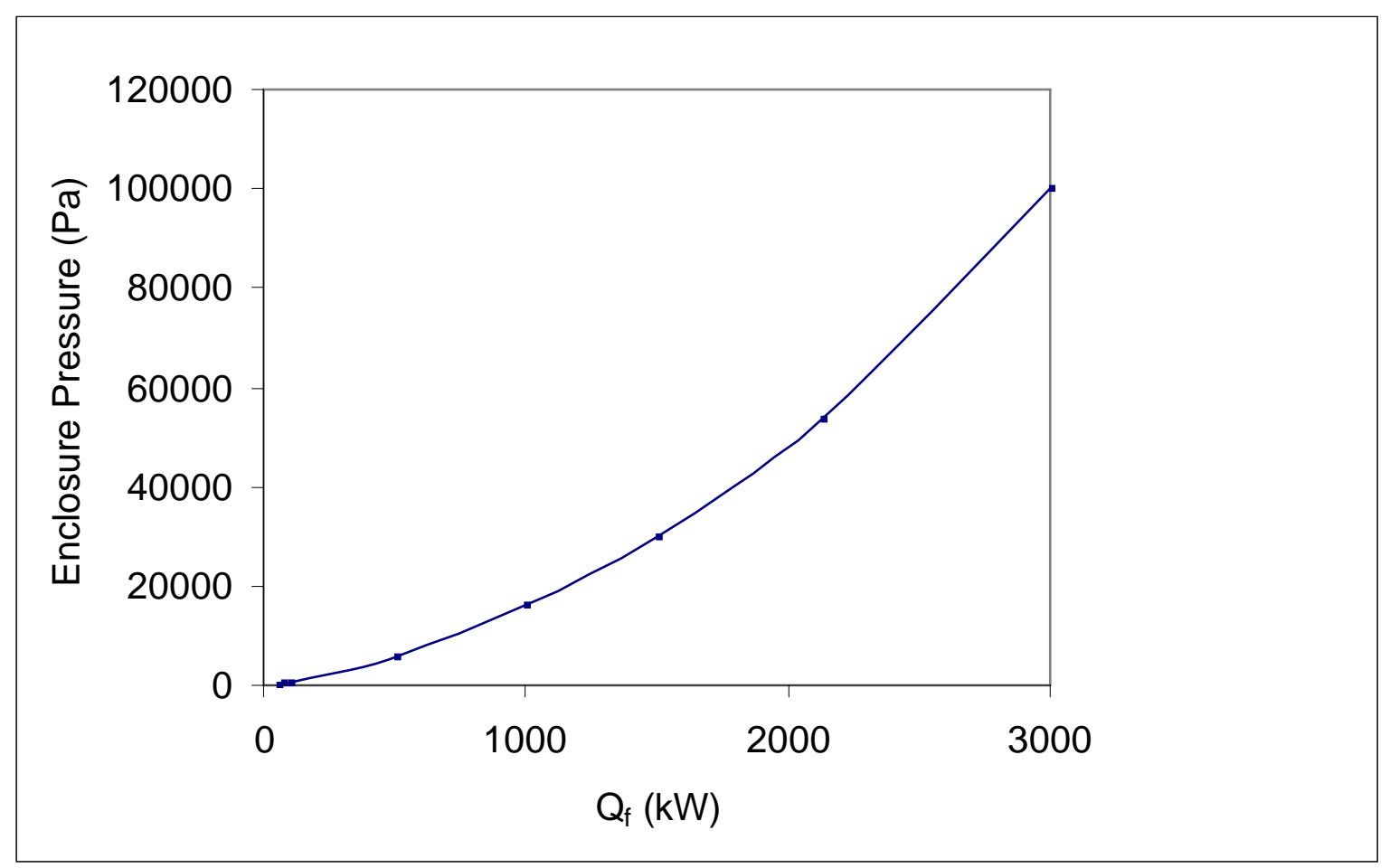

Figure 15. The calculated enclosure pressure as a function of the fire heat release rate $95 \mathrm{~ms}$ after fire initiation for a $12.7 \mathrm{~cm}$ (5 in) vent hole size.

If only the dry bay volume is considered, the required fire heat release rate to obtain the same enclosure pressures resulting in failure would be approximately $1 \mathrm{MW}$, whereas a pressure of $30 \mathrm{kPa}$ (4.3 psig) would be obtained for a fire size of $800 \mathrm{~kW}$. A smaller vent size would require a correspondingly smaller fire heat release rate to obtain the same enclosure pressure. A $1 \mathrm{MW}$ fire would require burning an average of approximately $20 \mathrm{~kg}$ of jet fuel per second. This may not be an unreasonable value considering the quantity of fuel available $(160000 \mathrm{~L})$ and the volume of the dry bay $\left(\approx 3 \mathrm{~m}^{3}\right)$. For turbulent hydrocarbon pool fires, heat release rates per volume are typically $1200 \mathrm{~kW} / \mathrm{m}^{3}$ to $2500 \mathrm{~kW} / \mathrm{m}^{3}$ depending on the measurement technique used [de Ris, 1979; Orloff and de Ris, 1983]. It is not unreasonable to expect comparable values for a turbulent spray fire (composed of many small non-premixed flames associated with burning droplets) burning in a $3 \mathrm{~m}^{3}$ volume. 
The internal investigation of the dry bay incident suggested that the release of agent ( $\mathrm{N}_{2}$ in this case) acted to mechanically agitate the air contributing to a more vigorous and rapid combustion event. A detailed understanding of the exact nature of this event for the purposes of this report has been hampered by the availability of detailed specific information on the conditions and geometry of the incident in question. This is largely due to the availability of documents associated with the test program and the investigation itself. The documents that were made available are consistent with the conclusions of the internal investigation at Wright Patterson AFB described above. It should be emphasized, however, that the lack of an effective amount of agent precipitated the over-pressurization event. Contributing to the situation is the fact that $\mathrm{N}_{2}$ is not an effective suppressant, requiring almost 4 times more agent by volume than HFC-125, for example, to extinguish a heptane cup burner flame [Hamins et al., 1994] and at the volume fractions used in this experiments, suppression was extremely unlikely. It should also be noted, that over-pressurization was typical during these experiments. The difference in the catastrophic incident was that the over-pressurization was more intense than over-pressurization due to the agent alone or due to the projectile impact alone. The pressure data from 12 experiments showed that over-pressures greater than $48 \mathrm{kPa}$ occurred during two experiments. The catastrophic C130 test was unique in that the agent amount was too small to be effective, but the lack of suppressant was not the lone contributor to the pressure increase in this incident. An analysis of a series of baseline experiments associated with this program in the C130 dry bay Simulator suggests that there was a non-negligible probability of large (> $54 \mathrm{kPa}$ ) static pressure increases just from the projectile impact. Unfortunately, these data are not available for general release. Clearance issues such as this hampered progress and communication of results associated with this study.

\subsubsection{Summary}

In summary, the simplified global analysis yields two interesting results, namely that a moderate difference in $\dot{q}_{f}$ could have caused failure of the fixture and that paradoxically, the pressure rise is larger for smaller vent sizes (small diameter projectiles). The results suggest that a pressure rise strong enough to cause the over- 
pressurization and apparatus failure was likely due to suppressant $\left(\mathrm{N}_{2}\right)$ induced mixing leading to enhanced combustion. A more complete analysis would consider compressibility and dynamic effects.

\subsection{Case 3: Pressure Fluctuations During Suppression in an Enclosure}

The experiments performed by Kashiwagi et al. [2000] on suppression of

moderate-sized ( $\approx 200 \mathrm{~kW}$ ) hydrocarbon pool-fires burning in an enclosure are examined below. A schematic drawing of the experimental apparatus taken from Kashiwagi et al. [2000] is shown in Fig. 16. Twenty experiments were conducted using five types of suppressant including HFC-227ea, HFC-23, and the inert mixtures, IG-541 (52 \% $\mathrm{N}_{2}$, $40 \%$ Ar, $8 \% \mathrm{CO}_{2}$ ), IG-55 (50 \% N used a different type of nozzle. The mass of suppressant discharged was approximately $20 \%$ above cup burner values. The design volume fraction varied from $38 \%$ to $41 \%$ for the inert suppressants, 8 \% for HFC-227ea, and $16 \%$ for HFC-23. In the experiments, $30 \mathrm{~kg}$ to $45 \mathrm{~kg}$ of suppressant was discharged from a pressurized cylinder over a period varying from $10 \mathrm{~s}$ to $105 \mathrm{~s}$ depending on the suppressant type with the inert

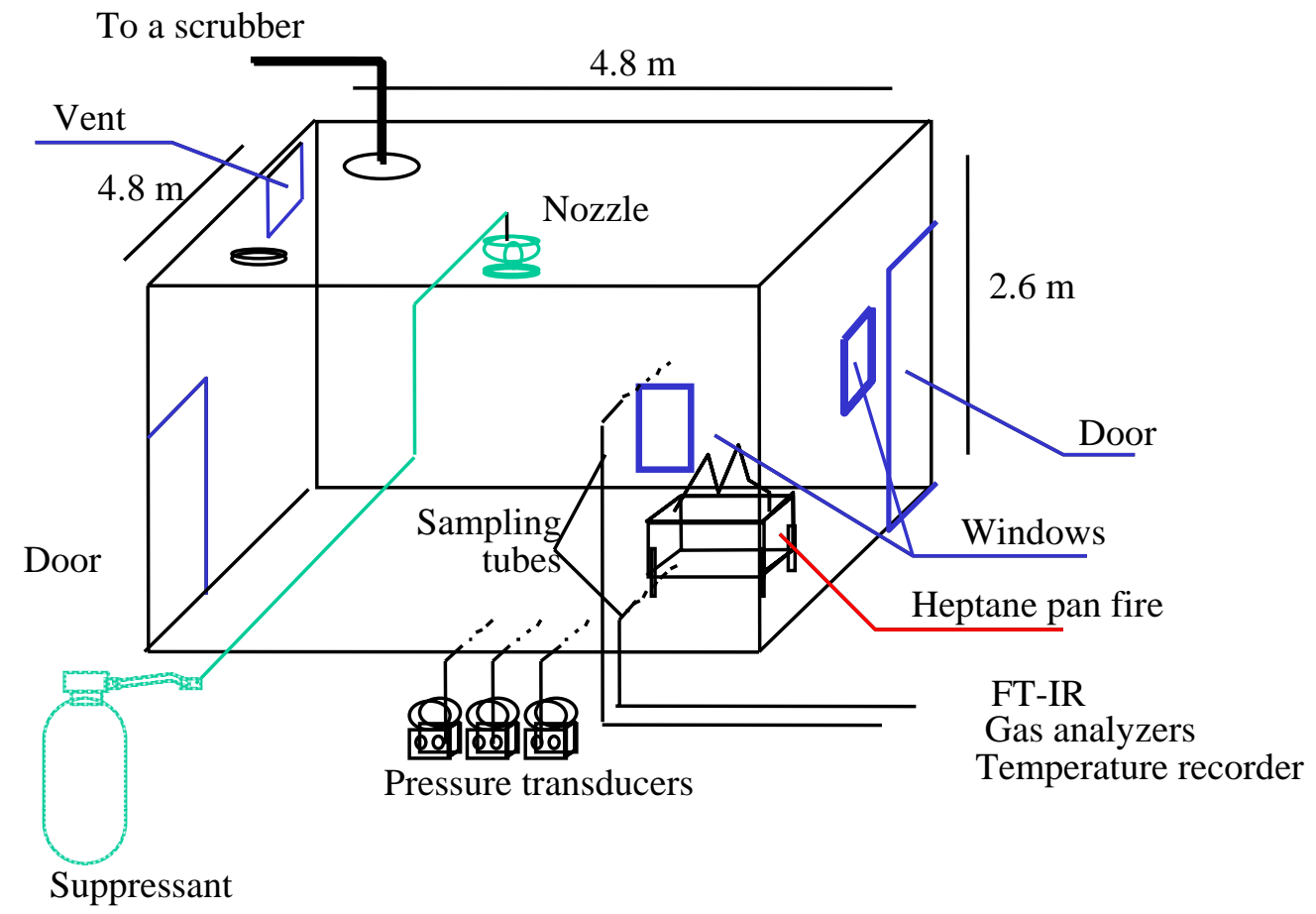

Figure 16. Schematic diagram of the enclosure suppression experiment taken from Kashiwagi et al. [2000]. 
suppressant taking $55 \mathrm{~s}$ or longer. Suppressant effectiveness was tested for heptane pool fires varying from approximately $200 \mathrm{~kW}$ to $400 \mathrm{~kW}$. A number of experiments were also conducted using wood cribs. The fire was ignited with the door open and the vent closed. The vent was spring activated, responding to the enclosure pressure. The exact response function was not characterized. This is unfortunate as the enclosure pressure is highly sensitive to the vent opening.

Approximately $10 \mathrm{~s}$ before suppressant discharge, the door was closed.

Simultaneously, the vent began to open. No controlled ignition source was present in the enclosure, although the hot metal of the burner or fire-heated thermocouples could have acted as an ignition source. A complete description of the procedure and the experimental results is given in Kashiwagi et al. [2000]. Pressure fluctuations as large as $1 \mathrm{kPa}$ to $3 \mathrm{kPa}$ in the enclosure were measured during the experiments [Kashiwagi et al., 2000]. A typical pressure trace is shown in Fig. 17. The maximum size of the pressure fluctuations in these experiments was an order of magnitude smaller than in the two other cases considered in this report (Sections 5.1 and 5.2). The reasons for the pressure fluctuations are not clear. It is possible, however, that the fluctuations were due to dynamics of the suppressant flow shielding air from fuel. Of course, the pressure traces reported by Kashiwagi et al. [2000] are for successful suppression tests only. Unsuccessful suppression may have led to over-pressures not unlike those observed in the first two cases of this report. In this sense, the Kashiwagi's results are consistent with the first two cases examined in this report - large over-pressures did not occur when suppression was successful.

Pressure excursions were observed when both halogenated or inert agents were applied. The pressure fluctuations are attributed to the dynamic nature of the suppression process in which a portion of the enclosure volume is suppressed successfully. As fuel vapor flows from the liquid puddle, reacting with available air, excursions in pressure occur as local combustion occurs.

Attempts to recreate aspects of the experiments including the pressure fluctuations using the NIST Fire Dynamics Simulator (FDS) software were largely unsuccessful. FDS is a large-domain CFD fire model that predicts and visualizes the spread, growth, and suppression of a fire for practical engineering applications based on the underlying 
scientific principles governing fluid motion. The model solves numerically the conservation equations of mass, momentum, and energy that govern low-speed, thermally-driven flows with an emphasis on smoke and heat transport from fires. The code addresses combustion and hydrodynamic phenomena over a range of physical length scales varying six orders of magnitude. In common usage, FDS employs either a mixture fraction model (infinite rate chemistry) or simplified finite rate chemistry. Here, single step chemistry was employed. Depending on the kinetic rates selected, almost any type of dynamic enclosure pressure result was possible. Using Arrhenius rate parameters that correspond to measurements in small-scale experiments failed to yield pressure fluctuations similar to those observed by Kashiwagi et al. [2000]. Flame suppression phenomena take place on the physical length scale of a flame sheet, which is on the order of $1 \mathrm{~mm}$ in length and is over an order of magnitude smaller than the grid size that is practical for CFD fire models such as FDS. Further work is needed to develop robust fire suppression models for large-scale fire phenomena.

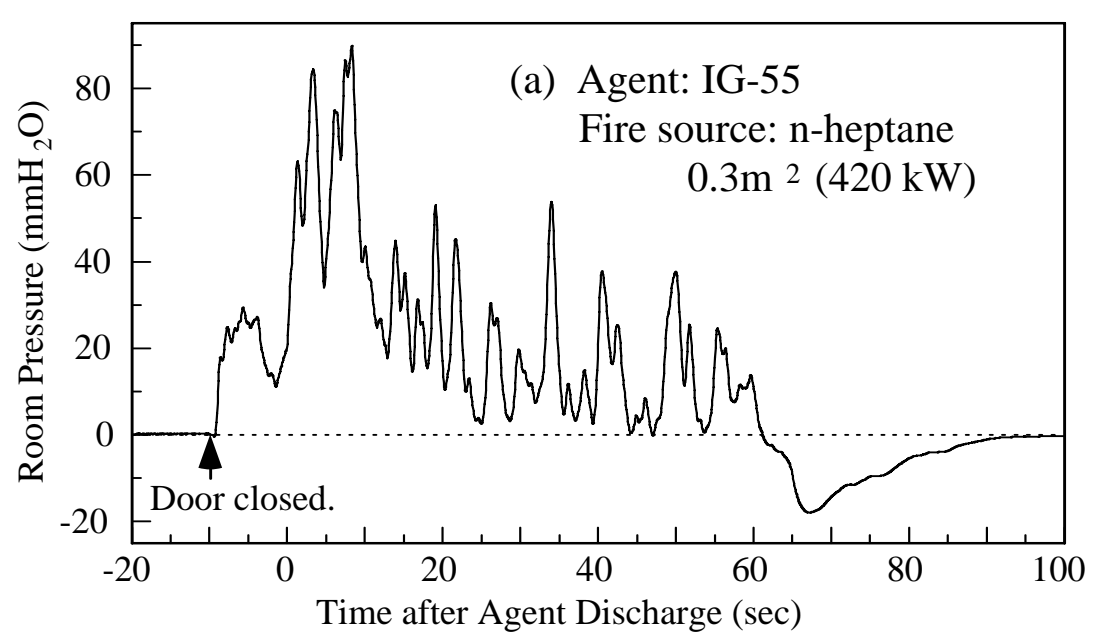

Figure 17. The room pressure measured experimentally for the case of a heptane pan $\left(0.3 \mathrm{~m}^{2}\right.$ area) fire $(420 \mathrm{~kW})$ suppressed by an inert suppressant mixture. The figure is taken directly from Kashiwagi et al. [2000]. 


\subsection{Accelerated Burning in Engine Nacelles}

Because of the serious hazard posed by over-pressurization of an enclosure as exemplified through the dry bay incident described in the previous section, this section first considers this phenomenon. Interviews with those performing full-scale experiments in engine nacelles and those working in the aircraft industry suggest that there has never been a case of over pressure damage associated with agent release in an engine nacelle. According to a Boeing representative, nacelle failure due to suppressant deployment has never been recorded [Rosenfelds, 2002]. Nacelles are designed to handle catastrophic failure of the bleed air duct, which connects the nacelle to the engine itself. For this reason, actual nacelles include blow-out panels and ports that are designed to rapidly open in response to significant pressure increases due to rapid additions of large flows into the nacelle [Rosenfelds, 2002].

Structural damage to a nacelle may occur due to weather, foreign object impact (birds, projectile) or catastrophic engine failure (core components shred), but structural damage due to over-pressurization from suppressant deployment and fire is improbable [Ingerson, 2002]. Finally, nacelle fires are not expected to be as large as dry bay fires. Agent quantity is designed to produce a specified or designed volume fraction range. For these reasons, structural failure in a nacelle due to agent deployment is unlikely. During full-scale suppression testing at the Wright Patterson Engine Nacelle Facility, nacelle over-pressure during the F-22 program was not observed. Experiments during the F-22 experiments used a replica of the F-22 nacelle materials, geometry, and flow conditions. A typical pressure trace is shown in Fig. 18. The experiment involved a jet fuel spray flame extinguished by a solid propellant gas generator (SPGG) released at time zero in the figure. In these experiments, the pressure increase never exceeded $3 \mathrm{kPa}$ to $7 \mathrm{kPa}$. Other suppression experiments at the Wright Patterson facility over the last few years have not led to system over-pressurization, structural damage to the facility, or blow-out of rupture panels [Tucker, 2002]. These results are consistent with Boeing's contention that nacelle failure due to suppressant deployment is highly unlikely [Rosenfelds, 2002]. 


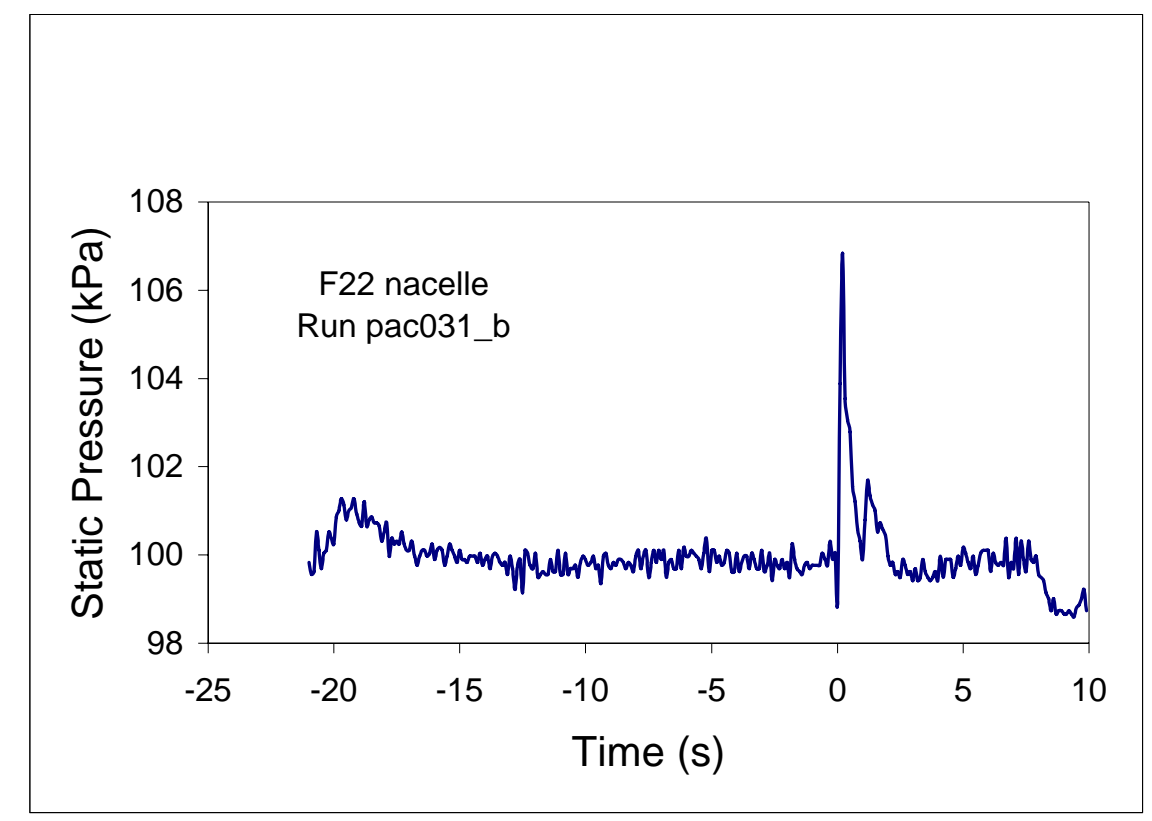

Figure 18. Pressure trace taken during the 1997 F22 engine nacelle test program at Wright Patterson Air Force Base.

\section{Summary and Conclusions}

A literature review and survey of practitioners suggested that there are several mechanisms associated with accelerated burning after suppressant delivery. An analysis of the information suggests that the main hazard of accelerated burning is system overpressurization due to enhanced combustion from vaporizing fuel that mixes with air after suppressant delivery. Small amounts of over-pressurization are not problematic, but if the over-pressurization is large, then damage of a structural element may occur. Depending on the location and function of the structural element, over-pressurization may impact aircraft function.

The phenomenon associated with enhanced burning after suppressant delivery is of considerable importance and certainly can impact strategies and mass requirements associated with fire suppression in aircraft applications. It is important to note that each

of the possible mechanisms of unwanted enhanced burning after suppressant delivery that are described in Section 1 may occur not only in actual engine nacelles and dry bays, but can also be expected to occur during full-scale suppression testing. In this sense, it is expected that accelerated burning effects are already embedded in the full-scale test 
results and therefore in the design equations that are based on those results. With this recognition, a central question becomes, how well do the current generation of full-scale fire suppression tests represent the range of conditions experienced in the field? If a fire test program considers a broad range of conditions that incorporates all conditions experienced in the field, then that aspect of the test program should be considered adequate. On the other hand, if a fire test program does not consider a broad range of conditions, then such a program should be considered lacking. Fire conditions in fullscale suppression tests should be carefully designed to include a worst case or else unwanted burning effects may occur under extreme conditions that were unanticipated during a full-scale test program.

Based on this conclusion, it is recommended that full-scale fire suppression testing be founded on a comprehensive scientifically-based design process rather than on an ad-hoc basis, which has historically been the case. The design of full-scale fire suppression test scenarios ought to use the best analytic and computational tools available, which may require a significant portion of the resources of any test program. Currently, full-scale fire suppression testing is an art. It needs to integrate scientific analysis in the design of experiments and interpretation and analysis of experimental results.

A high momentum suppressant discharge was shown to be advantageous in terms of reducing the total mass required to suppress a fire. The splashing of fuel associated with suppressant discharge could present a mechanism of fire spread and enhanced combustion. There is no evidence, however, that shows that suppression is not possible using a high momentum discharge towards a fuel puddle in a dry bay or nacelle, given sufficient suppressant. Appropriate safety factors should be determined and applied in fire suppression systems design to avoid unwanted enhanced burning effects. Still, it may be prudent to direct a high momentum suppressant discharge away from a fuel source provided that adequate spatial coverage by the suppressant is not compromised. This should prove to be feasible in both nacelles and dry bays.

In summary, the main hazard associated with enhanced burning after suppressant delivery is system over-pressurization likely due to rapid mixing of fuel vapor with air. Insufficient suppressant delivery and enhanced mixing can lead to enhanced burning, 
depending on the circumstances. Unwanted burning effects did not appear to occur when sufficient suppressant was applied to assure suppression and prevention of re-ignition. Assuring that sufficient suppressant is delivered to the fire can minimize enhanced burning hazards.

To reiterate the most important conclusion of this work, unwanted accelerated burning effects are already embedded in full-scale test results and the resulting design equations. Further research is needed to develop accurate general-purpose CFD models of fire suppression. This study demonstrates the need for data to better predict flammability limits, especially at elevated temperature.

\section{Acknowledgements}

The authors are indebted to Donald Bein (NAVAIR), Mike Bennett (WPAFB), Linda Blevins (SANDIA), Dan Cyphers (Skyward Ltd ), Doug Ingerson (FAA), Alexander Maranghides (NIST), Joe Manchor (China Lake), Bill Pitts (NIST ), Kuldeep

Prasad (NIST), Ron Sheinson (NRL), Yuko Saso (FRI), and Jiann Yang (NIST) for many helpful discussions and suggestions. 


\section{References}

Bennett, M., Wright Laboratory, Personal Communication, Wright Patterson Air Fire Base (2002).

Cyphers, D.C., “C-130 Vulnerability Reduction Program (VRP) Baseline Test WLE-RB-07 Investigation, Phase 1 - Wing Dry Bay Fire Extinguishing Agent Evaluation, Phase 1A - Wing Leading Edge Dry Bay Testing”, Wright-Patterson Air Force Base, Ohio, October 1998.

de Ris, J., The Seventeenth Symp. (Int.) on Combustion, The Combustion Institute, pp. 1003, 1979.

Gordon, S. and McBride, B.J., Computer Program for Calculation of Complex Chemical Equilibrium Compositions, Rocket Performance, Incident and Reflected Shocks, and Chapman-Jouget Detonations, NASA SP-273, 1976.

Hamins, A., Gmurczyk, G., Grosshandler, W., Rehwoldt, R.G., Vazquez, I., Cleary, T., Presser, C., and Seshadri, K., “Flame Suppression Effectiveness,” in Evaluation of Alternative In-Flight Fire Suppressants for Full-Scale Testing in Simulated Aircraft Engine Nacelles and Dry Bays, Grosshandler, W.L., Gann, R.G., and Pitts, W.M., eds., NIST SP 861, pp. 813-826 (1994).

Hamins, A., Presser, C., and Melton, L., "Suppression of a Baffle Stabilized Spray Flame by Halogenated Agents," The Twenty-Sixth Symp. (Int.) on Combustion, The Combustion Institute, pp. 1413-1420, 1996.

Han, Kim, and Shin, “Experiments on the Interaction of Water Sprays with Pool Fires,” Proc. Int. Sym. on Fire Sci. \& Tech., 518-525, 1997.

Haas, J.P., “C-130 Vulnerability Reduction Program, C-130j Live Fire Test Program Test Report, Phase 1 - Wing Dry Bay Fire Extinguishing Agent Evaluation, Phase 1A Wing Leading Edge Dry Bay Testing,” \#AAC TR 00-14, Wright Patterson AFB, OH, July 2000.

Holmstedt, G., Andersson, P., and Andersson, J., "Investigation of Scale Effects on Halon and Halon Alternatives Regarding Flame Extinguishing, Inerting Concentration and Thermal Decomposition Products," Fire Safety Science-Proceedings of the Fourth International Symposium, pp. 853-864 (1994). 
Holmstedt and Anderson, "Alternative Agent Combustion Product Formation, Flame Suppression and Flammability Characteristics” Halon Alternatives Technical Working Conference, 83-106, 1993.

Ingerson, D. personal communication, Department of Transportation, Federal Aviation Administration (FAA), WJ Hughes Technical Center, Atlantic City Int'l Airport, NJ, 2002.

Kashiwagi, H., Oshikawa, S., Yui, J., and Saso, Y., "Effect of Fire Size on Suppression Characteristics of Halon Replacement Total-Flooding Systems," Halon Options Technical Working Conference (HOTWC), Albuquerque, NM, April 2001; and the companion report, "Report of the Research Committee for Establishment of Safety Standards on Halon Replacement Agents,” The Japanese Fire Equipment Inspection Institute, Fire and Disaster Management Agency, March 2000.

Kim, M. B., Jang, Y.J., and Kim, J.K., "Burning Rate of a Pool Fire with Downwarddirected Sprays," Fire Safety Journal 27, pp. 37-48 (1996).

Kokkala, Matti A., "Fixed Water Sprays Against Open Liquid Pool Fires,” Proceedings of the First International Conference on Fire Suppression Research, Sweden, pp. 129158 (1992).

Kolleck, M., Booz-Allen-Hamilton tabulated survey results of present aircraft systems and operating environments, (1993).

Kim, Jang, Y.J., and Yoon, "Extinction Limit of a Pool Fire with a Water Mist," Fire Safety J., 28, 295-306, 1997.

Macek, A., Flammability Limits: Thermodynamics and Kinetics, NBSIR 76-1076, May 1976.

Manchor, J., Personal Communication, Aircraft Survivability Division, U.S. Navy, China Lake, CA, 2002.

Manzello, S., and Yang, J., Int. J. Heat and Mass Transfer, 45, 3961-3971, 2002.

Maranghides, A., Personal Communication, Aircraft Survivability Division, U.S. Navy, China Lake, CA, 2002. 
Maranghides, A. and Sheinson, R., "Deflagration Induced During Total Flooding Halon Replacement Suppression,” Fire Safety Science-Proceedings of the Sixth Int. Sym., IAFSS, p. 1199, 2000.

McGrattan, K., Baum, H.R., Rehm, R.G., Hamins, A., and Forney, G.P., Fire Dynamics Simulator-Technical Reference Manual, NIST Internal Report NISTIR 6467, National Institute of Standards and Technology, Gaithersburg, MD, January 2000.

Orloff, L., and De Ris, J., The Nineteenth Symp. (Int.) on Combustion, The Combustion Institute, pp. 885, 1983.

Pitts, W.M., "Reynolds Number Effects on the Mixing Behavior of Axisymmetric Turbulent Jets,” Experiments in Fluids 11, 135-141, (1991).

Pitts, W. M., Yang, J. C., Gmurczyk, G., Cooper, L.Y., and Grosshandler, W. L., "Fluid Dynamics of Agent Discharge," in Evaluation of Alternative In-Flight Fire Suppressants for Full-Scale Testing in Simulated Aircraft Engine Nacelles and Dry Bays, Grosshandler, W.L., Gann, R.G., and Pitts, W.M., eds., NIST SP 861, pp. 813826 (1994).

Rehm, R.G. and Forney, G., "A Note of the Pressure Equations used in Zone Fire Modeling,” NISTIR 4906, Aug. 1992.

Rosenfeld, S., personal communication, Boeing Aircraft, Seattle, WA, 2002.

Saso, Y., personal communication, Research Institute of Fire and Disaster (RIFD), Mitaka, Tokyo, Japan, 2002.

Sheinson, R.S., Personal Communication, Aircraft Survivability Division, U.S. Navy, China Lake, CA, 2002.

Sheinson, R.S., Eaton, H. G., Black, Bruce H., Brown, R., Burchell, H., Salmon, G., St. Aubin, J., and Smith, W.D., “Total Flooding Fire Suppressant Testing in a $56 \mathrm{~m}^{3}$ (2000 $\mathrm{ft}^{3}$ ) Compartment," in Proceedings of Halon Alternatives Technical Working Conference, Albuquerque, New Mexico, pp. 137-148 (1993).

Smyth, K. C., and Everest, D. A., "The Effect of $\mathrm{CF}_{3} \mathrm{I}$ Compared to $\mathrm{CF}_{3} \mathrm{Br}$ on $\mathrm{OH}$ - and Soot Concentrations in Co-Flowing Propane/Air Diffusion Flames,” Twenty-Sixth Symposium (International) on Combustion, pp. 1385-1393 (1996). 
Tedeschi, M., personal communication, Naval Air Warfare Center Aircraft Division (NAVAIR), Lakehurst, NJ, 2002.

Trabold, T.A. and Obot, N.T., "The Onset of Splashing from Free Liquid Surfaces Exposed to Impinging Gas Jets,” Proc. ASME Fluids Eng. Div. Summer Meeting (FEDSM’97). Part 16, Paper No. FEDSM 97-3561, Jun 22-26, 1997, Vancouver, Can.

Tucker, J., Wright Laboratory, Personal Communication, Wright Patterson Air Fire Base (2002).

Wolf, J., personal communication, Naval Air Warfare Center Aircraft Division (NAVAIR), Lakehurst, NJ, 2002.

Yang and Pitts, “Agent Discharge above a heptane pool fire” personal communication, 1994.

Yang, J.C., Cleary, T.G., Vazquez, I., Boyer, C.I., King, M.D., Breuel, B.D., Womeldorf, C.A., Grosshandler, W.L., Huber, M.L., Weber, L., and Gmurczyk, G., “Optimization of System Discharge,” in Fire Suppression System Performance of Alternative Agents in Aircraft Engine And Dry Bay Laboratory Simulations, Gann, R.G., ed., NIST SP 890: Vol. I, pp. 407-781 (1995). 